\title{
What Divides, and What Unites, Right-Node Raising
}

Zoë Belk, Ad Neeleman and Joy Philip (UCL)

We argue, following Barros and Vicente (2011), that right-node raising (RNR) results from either ellipsis or multidominance. Four considerations support this claim. (i) RNR has properties of ellipsis and of multidominance. (ii) Where these are combined, the structure results from repeated RNR: a pivot created through ellipsis contains a right-peripheral secondary pivot created through multidominance. (iii) In certain circumstances, one or the other derivation is blocked, so that RNR behaves like pure ellipsis or pure multidominance. (iv) Linearization of RNR-as-multidominance requires pruning. The same pruning operation delivers RNR-as-ellipsis, which explains why the two derivations must meet the same ordering constraints. Keywords: right-node raising, multidominance, ellipsis, coordination.

\section{Introduction}

Right-node raising (RNR) is a construction that seems stranger the longer one considers its behavior. It displays a combination of syntactic properties that do not fit any known syntactic operation in English and is moreover subject to very strict word order constraints that seem sui generis. This paper aims to bring us closer to an understanding of the construction. While we may not be able to return RNR to normalcy, we demonstrate that a coherent analysis is available - an analysis whose components are familiar from other phenomena in English syntax.

We argue, following Barros and Vicente (2011), that RNR can be the output of two distinct derivations. On one derivation, a category left unrealized in the mapping to PF is recovered through the pivot (the category that appears in the right periphery). On the other derivation, the pivot is a category dominated by two nodes. The two options are illustrated below for John likes, and Mary dislikes, opera. 
(1)

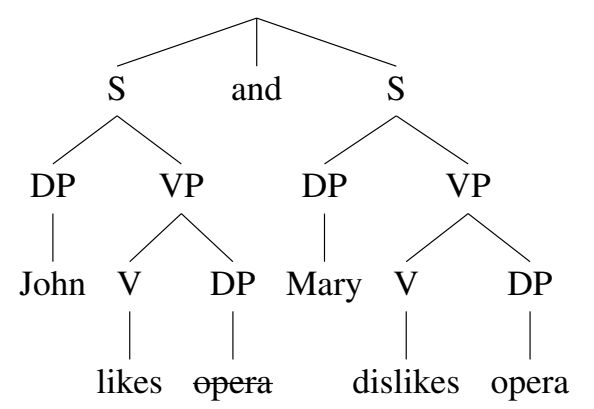

Right-node raising as ellipsis (RNR-E)

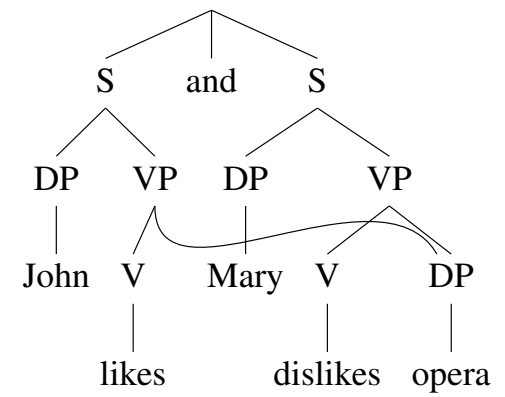

Right-node raising as multidominance (RNR-MD)

We follow much of the literature in assuming that ellipsis in general results from the non-realization of syntactic structure at PF, rather than from the absence of syntactic structure altogether (for discussion and references, see Van Craenenbroeck and Temmerman 2018). Thus, the ellipsis site in RNR-E lacks phonology, but has a syntactic structure similar to its overt counterpart.

A dual analysis of the type we advocate runs the risk of being rejected as unparsimonious if an empirically adequate unitary analysis is available. It must therefore be conceptually coherent and supported by strong evidence. This is a challenge given the intricacies of the construction. However, we believe that a convincing case can be made. We proceed as follows.

In section 2, we review and extend part of Barros and Vicente's argumentation. Barros and Vicente observe that the characteristics of RNR come in two sets. Characteristics in the first set are typical of ellipsis; they include a tolerance of vehicle change and of morphological mismatches. Characteristics in the second set go beyond what is permitted under ellipsis; they include cumulative agreement and the ability to license internal readings of relational adjectives. We argue that no unitary account can capture both sets of characteristics.

We then consider, in sections 3 and 4, why multidominance should give rise to cumulative agreement and the exceptional wide scope required to license internal readings of relational adjectives. We argue that cumulative agreement is an instance of semantic agreement available in multidominance structures because regular syntactic agreement is blocked there. We show that (parts of) the pivot can be assigned exceptionally wide scope because multidominance makes it possible to construct a bijective movement chain where LF raising would otherwise create a 
forking chain. The discussion will lead to the conclusion that no dual analysis other than one that combines ellipsis and multidominance can capture the characteristics of RNR.

In section 5, we consider under what circumstances RNR may combine properties indicative of ellipsis and properties indicative of multidominance. Barros and Vicente argue that such circumstances do not exist (that is, the two types of properties are mutually exclusive). Consequently, their proposal is often considered to have been falsified by the evidence for 'mixed' pivots in Larson 2012. We demonstrate, however, that a dual multidominance-plus-ellipsis account is subtler in its predictions than Barros and Vicente (and Larson) assume. This is because it is possible for a constituent at the right periphery of a pivot created through ellipsis to undergo RNR-MD. Consequently, properties indicative of multidominance may precede properties indicative of ellipsis, but not the other way around. We show that this linear asymmetry in the distribution of the two types of characteristics indeed exists.

In section 6, we show that, outside coordinate structures, RNR-MD is unavailable. This observation provides support for a dual multidominance-plus-ellipsis account, as it demonstrates that it is possible to selectively disable one of the processes that gives rise to RNR. Of course, the observation also raises the question of why coordination should be a precondition for RNRMD. We provide a speculative account, which is supported by the interpretation of so-called Horn amalgams (another construction often analyzed in terms of multidominance).

We conclude the main part of the paper in section 7 with a discussion of the issue of parsimony. Why should RNR, if it has two sources, give the impression of being a single phenomenon? Why should two very different processes (ellipsis and multidominance) be subject to very similar word order restrictions? No answer to this question is proposed in other papers advocating dual accounts (Barros and Vicente 2011, Valmala 2013, Chaves 2014 and Hirsch and Wagner 2015). Our proposal consists of a PF mapping rule (based on insights in Wilder 1999) that reconciles RNR-MD with the no-tangling condition. This rule prunes a branch that would otherwise cross other branches. The very same rule will yield RNR-E when applied to an appropriate 
input structure without multidominance. Thus, one incarnation of RNR is generated through a combination of multidominance and pruning, while the other involves pruning only. It follows that the two derivations will share properties associated with pruning, irrespective of their syntactic origin.

We end with a discussion of possible sources of crosslinguistic and inter-speaker variation in RNR grammars.

\section{The Duality of Right-Node Raising}

One question about RNR is whether the pivot remains in situ (as in (2a)) or is created through across-the-board (ATB) movement to a position outside the coordinate structure (as in (2b); see Ross 1967, Postal 1974, and Sabbagh 2007). ${ }^{1}$

(2) a. John likes and Mary [dislikes opera].

b. [John likes $t_{1}$ and Mary dislikes $t_{1}$ ] opera 1 .

Various linguists have argued that the ex-situ analysis is unlikely to be correct, because RNR lacks core properties of movement (Wexler and Culicover 1980, McCloskey 1986, Abels 2004, De Vos and Vicente 2005 and Citko 2011). First, as Abels (2004) notes, it is typical of overt movement operations that they lead to changes in word order. RNR, however, is obligatorily order-preserving. Given an input $\left[\mathrm{XP}_{1} \ldots \mathrm{Y} \ldots\right]$ and $\left[\mathrm{XP}_{2} \ldots \mathrm{Y} \ldots\right], \mathrm{RNR}$ can remove $\mathrm{Y}$ from $\mathrm{XP}_{1}$ if $\mathrm{Y}$ is right-peripheral in $\mathrm{XP}_{1}$ and $\mathrm{XP}_{2}$ (see (3a)). However, it is unable to shift $\mathrm{Y}$ rightwards across modifiers in $\mathrm{XP}_{1}$ and $\mathrm{XP}_{2}$ (see (3b)). It is of course suspect that a movement operation must preserve order in this way. ${ }^{2}$

(3) a. Yesterday Mary found a solution to, and next year John will write a book about, one of the great unsolved problems of syntax.

b. *Mary found a solution to yesterday, and John will write a book about next year, one of the great unsolved problems of syntax.

Second, Wexler and Culicover (1980) and many others have noted that RNR - in opposition to 
other instances of movement - is island-insensitive. On a movement account, (4a) would violate the wh-island constraint, (4b) would violate the complex-NP constraint and (4c) would violate the adjunct island constraint. Yet, all three examples are grammatical.

(4) a. John wonders when Bob Dylan wrote, and Mary wants to know when he recorded, his great song about the death of Emmett Till.

b. I know a man who buys, and you know a woman who sells, gold rings and raw diamonds from South Africa.

c. Josh got angry after he discovered, and Willow quit after she found out about, the company's pro-discriminatory policy.

Ross (1967) makes a related point, namely that preposition stranding is impossible under extraposition, as shown in (5), but permissible under RNR, as in (3a) above (see also McCloskey 1986):

(5) *Jane talked [about $t_{\mathrm{DP}}$ ] yesterday [DP the achievements of the syntax students].

Third, RNR, if it were a string-vacuous movement operation, should result in rebracketing. It can be shown, however, that it does not, at least not for ellipsis. As is well known, VP ellipsis can affect VPs containing a trace. In (6), for example, $e_{\mathrm{VP}}$ represents an unrealized instance of [vp read $t_{\mathrm{wh}}$ ] (see Merchant 2013 and references mentioned there).

(6) I know which book Mary read $t_{\mathrm{wh}}$ and which book Ryo didn't $e_{\mathrm{VP}}$.

If so, it should be possible on a movement analysis of RNR to elide the rightmost VP in (7a), leaving the pivot intact. However, the example in (7b) is ungrammatical. As Abels (2004) points out, this follows if the pivot is in fact contained in the rightmost VP - but that can only be the case if RNR does not in fact lead to rebracketing, unlike string-vacuous movement.

(7) a. Jane talked about, but Frank didn't talk about, the achievements of the syntax students. b. *Jane talked about, but Frank didn't $e_{\mathrm{VP}}$, the achievements of the syntax students. 
Given these considerations, we do not pursue a movement analysis of RNR. ${ }^{3}$

There are two unitary analyses that capture the above data, namely the ellipsis analysis in (1a) (Wilder 1997 and Hartmann 2000) and the multidominance analysis in (1b) (McCawley 1982, Wilder 1999 and De Vries 2009, a.o.). On both analyses the pivot remains in situ, so that RNR is expected to lack movement characteristics. Barros and Vicente (2011) demonstrate that neither of these unitary analyses can be correct, however. They discuss four additional properties of RNR. Two of these are shared with regular forward ellipsis but incompatible with a multidominance analysis. The other two are arguably compatible with multidominance but not shared with regular forward ellipsis. Hence, neither ellipsis nor multidominance can explain the full set of data.

The first property familiar from forward ellipsis is that RNR tolerates morphological mismatches between the overt and the missing material (see also Bošković 2004, Ha 2008 and Shiraïshi et al. 2019). One such mismatch involves the inflectional form of selected verbs. Consider the examples in (8). In (8a), the pivot is waking up early, which cannot appear following fail to when overt (see (8b)), but can act as an antecedent of wake up early in forward ellipsis (see (8c)).

(8) a. I usually fail to, but Ava always succeeds in waking up early.

b. *I usually fail to waking up early, but Ava always succeeds in waking up early.

c. Ava always succeeds in waking up early, but I usually fail to $e_{\mathrm{VP}}$.

Mismatches can also involve sloppy readings of pronouns. In (9a), for instance, the omitted material is naturally interpreted as pass my math exam, rather than pass her math exam. This interpretation is absent when the structure is fully realized, but acceptable under forward ellipsis (see $(9 \mathrm{~b}, \mathrm{c}))^{4}$

(9) a. I know that I didn't, but I'm sure that Ava will pass her math exam.

b. *I know that I didn't pass her math exam, but I'm sure that Ava will pass her math exam.

c. I'm sure that Ava will pass her math exam, but I know that I didn't $e_{\mathrm{vp}}$. 
RNR also resembles forward ellipsis in allowing vehicle change. The example in (10a) would violate principle $\mathrm{C}$ if the omitted material were fire Ava (see (10b)). Thus, a silent VP containing a pronoun (fire her) must be recoverable from an overt VP containing a coreferential R-expression, a phenomenon known from regular VP ellipsis (see (10c); see Fiengo and May 1994, a.o.).

(10) a. She ${ }_{1}$ hopes that he won't, but I fear that the boss will fire Ava.

b. *She $e_{1}$ hopes that he won't fire Ava 1 , but I fear that the boss will fire Ava.

c. I fear that the boss will [vp fire Ava 1 ], although she ${ }_{1}$ hopes that he won't $e_{\mathrm{VP} 1}$.

A unitary multidominance analysis cannot capture these data. While recoverability under ellipsis is relatively permissive, multidominance imposes an absolute identity requirement on the pivot and the 'gap': they are literally the same constituent. Hence, (8a), (9a) and (10a) are incorrectly predicted to be as bad as (8b), (9b) and (10b).

On the other hand, RNR differs from forward ellipsis in allowing cumulative plurals (see Postal 1998:173, Yatabe 2003, Chaves 2014 and Grosz 2015). Example (11a) is borrowed from Grosz (2015:16). Although the subject in each conjunct is singular, many speakers prefer it if the verb appears in the plural, seemingly reflecting the total number of people that have traveled to Cameroon. In regular forward ellipsis, cumulative agreement is not an option, as (11b) illustrates.

(11) a. Mary is proud that John, and Alma is glad that Ryo, have traveled to Cameroon.

b. John has $/ *$ have traveled to Cameroon, and Ryo $e_{\mathrm{TP}}$, too.

In addition, RNR permits an internal reading of relational adjectives like same and different, even though that reading is unavailable under regular ellipsis (Jackendoff 1977 and Abels 2004). Take an example like Ava and Beatrix performed different songs. On the external reading of different, Ava and Beatrix performed songs different from an unmentioned, contextually salient song. On the internal reading, Ava did not perform the song that Beatrix performed. Crucially, (12a) permits an internal reading of different, so that Beatrix performed a song different from the one that Ava com- 
posed. The example in (12b), which involves regular ellipsis, does not permit such an interpretation - it cannot mean that Beatrix performed a song different from Ava's song.

(12) a. Ava composed, and Beatrix performed, different ${ }_{\mathrm{INT}}$ songs.

b. *Ava performed different $\mathrm{I}_{\mathrm{INT}}$ songs, and Beatrix did $e_{\mathrm{VP}}$, too.

While it is not a priori clear that movement or multidominance can explain why RNR gives rise to cumulative agreement or internal readings of relational adjectives, there can be little doubt that ellipsis is unable to do so. Hence, none of the unitary analyses under consideration provides a feasible account of RNR. As indicated in the first three columns in the table below, movement, ellipsis and multidominance all leave some core observations unexplained.

\begin{tabular}{lcccccc}
\hline & Movement & Ellipsis & M-dominance & $\begin{array}{c}\text { Movement } \\
+ \text { ellipsis }\end{array}$ & $\begin{array}{c}\text { Movement }+ \\
\text { m-dominance }\end{array}$ & $\begin{array}{c}\text { Ellipsis + } \\
\text { m-dominance }\end{array}$ \\
\hline a. Order preservation & $\times$ & $\checkmark$ & $\checkmark$ & $\times$ & $\times$ & $\checkmark$ \\
b. Island insensitivity & $\times$ & $\checkmark$ & $\checkmark$ & $\checkmark$ & $\checkmark$ & $\checkmark$ \\
c. Non-rebracketing & $\times$ & $\checkmark$ & $\checkmark$ & $\times$ & $\times$ & $\checkmark$ \\
\hline d. Mismatches & $\times$ & $\checkmark$ & $\times$ & $\checkmark$ & $\times$ & $\checkmark$ \\
e. Vehicle change & $\times$ & $\checkmark$ & $\times$ & $\checkmark$ & $\times$ & $\checkmark$ \\
\hline f. Internal readings & $?$ & $\times$ & $?$ & $?$ & $?$ & $?$ \\
g. Cumulative Agr. & $?$ & $\times$ & $?$ & $?$ & $?$ & $?$
\end{tabular}

Table I: Provisional overview of the empirical coverage of unitary and dual analyses

The above observations give us a license to explore dual accounts of RNR. As things stand, the most promising dual account assumes that RNR is either the result of ellipsis (RNR-E) or of multidominance (RNR-MD), as advocated by Barros and Vicente. This hypothesis captures the observations in (Ia)-(Ie) and may be compatible with those in (If) and (Ig).

An account along these lines also sheds light in the intonation of RNR structures (cf. Valmala 2013). Both RNR-MD and RNR-E require a short prosodic break between conjuncts. 
In examples putatively resulting from RNR-MD (such as (11) and (12)), an additional prosodic break at the onset of the pivot is obligatory. Where a pivot displays properties indicative of ellipsis (as in (8) and (9)), however, the preference is for no pre-pivotal prosodic break, this preference being particularly strong in the case of vehicle change (as in (10)).

Alternative dual accounts that hypothesize that ATB movement is one source of RNR (see Valmala 2013 and Chaves 2014) cannot explain order preservation or lack of rebracketing. In addition, a movement-plus-multidominance account cannot capture the observed tolerance of mismatches or the option of vehicle change, as these are incompatible with either multidominance or movement. As already explained, the incompatibility with multidominance is a matter of logic. The incompatibility with movement has not been demonstrated yet. However, it is implied by the copy theory and supported by the data in (13).

(13) a. *Waking up early, Ava always succeeds in $t_{\mathrm{vP}}$, but I usually fail to $t_{\mathrm{VP}}$.

b. *Passing her math exam, I'm sure that Ava will succeed in $t_{\mathrm{vP}}$, but I know that I have failed at tip.

c. *Firing Ava 1 , I fear that the boss is thinking of $t_{\mathrm{vp}}$, but she ${ }_{1}$ hopes that he won't consider $t_{\mathrm{VP}}$

The above encourages us to explore the ellipsis-plus-multidominance account of RNR. Whether this account stands up to closer scrutiny depends on various issues. To begin with, there are two properties of RNR that require further discussion: its ability to license cumulative agreement and internal readings of relational adjectives. Barros and Vicente suggest that these properties follow from multidominance, but it is not a priori clear why this should be so (hence the question marks in table I). We address these matters in the following two sections.

\section{Multidominance and Cumulative Agreement}

Why should RNR-MD give rise to cumulative agreement? Why should plural marking be li- 
censed in examples such as (11a) (repeated here as (14)), even though each conjunct has a singular subject?

(14) Mary is proud that John, and Alma is glad that Ryo, have traveled to Cameroon.

We consider two hypotheses. The first, due to Grosz (2015), is that multidominance leads to a structure in which a verb agrees twice (see Yatabe 2003 for a similar analysis within HPSG). Thus, have in (14) agrees both with John and with Ryo. These two singular agreement relations are added up (in a way to be made precise below) to yield a plural ending. The second hypothesis, which we will argue for, is that multidominance leads to a structure in which the verb cannot agree at all. This, then, leads to a situation in which the information on the verb must be interpreted, triggering a requirement of plurality if the verb is marked plural.

Grosz's analysis of cumulative agreement under RNR can be summarized as follows. (i) A multidominated predicate agrees with multiple subjects. (ii) Plural DPs have multiple indices; singular DPs have a single index. (iii) Under agreement, all the indices of the agreeing subject(s) are copied into an agreement slot. (iv) An agreement slot is an unordered set of indices whose arity is reflected by morphological number.

Thus, in (14) the indices of John and Ryo are copied into the predicate's agreement slot. As these indices are distinct, the arity of the agreement slot is larger than one, and therefore the auxiliary assumes its plural form:

(15) Mary is proud that $\operatorname{John}_{\{j\}}$, and Alma is glad that $\mathrm{Ryo}_{\{\mathrm{r}\}}$, have ${ }_{\{, \mathrm{j}\}}$ traveled to Cameroon.

This analysis predicts correctly that if in a comparable structure the two subjects bear the same index, agreement will be singular. In (16), for example, the index of John is copied twice. These indices are not distinct, so the arity of the agreement slot is one $(\{\mathfrak{j}, \mathrm{j}\}=\{\mathrm{j}\})$. Consequently, insertion of a plural auxiliary is not warranted.

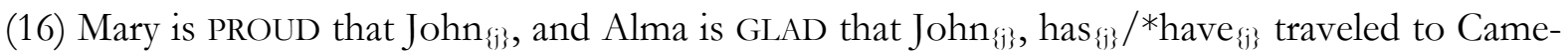
roon. 
While ingenious in its syntacticization of cumulative agreement, this analysis falls short in one crucial respect. To see this, consider (17). Here, the context makes clear that a single person has traveled to Cameroon, while the example sentence describes a disagreement over the question of who this person is. As it turns out, under these circumstances the auxiliary cannot carry plural morphology. This does not follow. Ryo and Carla have different indices, and therefore the arity of the auxiliary's agreement slot will be larger than one, which should trigger plural marking.

(17) One of our neighbors has traveled to Cameroon, but we do not know who.

John said that RYO, but Mary said that CARLA, has/*have traveled to Cameroon.

The effect is not limited to instances of RNR with but as coordinator. There is a clear contrast between (18a), where the assumption is that a single person has stolen a unique backdoor key, and (18b), where the assumption is that multiple persons have stolen copies of the backdoor key. Only the second scenario allows plural marking of the predicate, even though the structures are syntactically identical, and both have and as a coordinator.

(18) a. Someone has stolen the backdoor key, but we do not know who.

John said that RYO, and Ryo said that JOHN, has/*have stolen the backdoor key.

b. Several people have stolen backdoor keys, and we know who some of them are.

Mary discovered that Ryo, and Carla discovered that John, have stolen backdoor keys/a backdoor key.

Thus, cumulative agreement is sensitive to whether the predicate is supposed to hold of a plural individual, a fact at odds with the index copying mechanism in Grosz (2015).

Our alternative starts from the notion that multidominance blocks agreement altogether. We implement this idea as follows. First, we take agreement to be a relation of feature identification, a hypothesis familiar from HPSG, LFG and certain strands of minimalism (Gazdar et al. 1985, Shieber 1986, Barlow 1992, Pollard and Sag 1994, Brody 1997 and Ackema and Neeleman 
2018). Thus, in the boys bave left, the plural feature of the auxiliary is identified with the plural feature of the DP, resulting in a single feature that has two locations. Second, features are interpreted in a unique location. Thus, in the boys have left the plural feature must be interpreted in the subject or in the auxiliary, but not in both. Third, $\varphi$-features in DPs must be interpreted. Thus, in the boys have left, the plural feature is interpreted in the DP and not in the auxiliary. Fourth, agreement is greedy: if a verbal head probes a domain for relevant features, it must agree with any category accessible to it (see Ackema and Neeleman 2018 on the direction of agreement).

Consider now what happens if the pivot in a multidominance structure contains a verbal head that probes for phi features, as in (19).

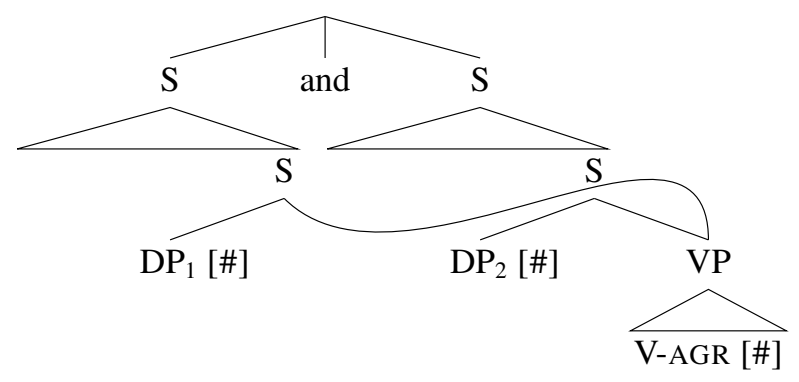

What is unusual about this situation is that there are multiple categories that $\mathrm{V}$ can and therefore must agree with (given our fourth assumption). In (19), these are the subjects $\mathrm{DP}_{1}$ and $\mathrm{DP}_{2}$. Consequently, the number feature of $\mathrm{V}$ is identified with both the number feature of $\mathrm{DP}_{1}$ and the number feature in $\mathrm{DP}_{2}$. By transitivity, the number features of $\mathrm{DP}_{1}$ and $\mathrm{DP}_{2}$ are identified as well, so that we arrive at a representation in which a single feature has three locations. It can only be interpreted in one of these locations (by our second assumption) but must be interpreted in both DPs (by our third assumption). Therefore, $\mathrm{V}$ cannot act as a probe in (19).

We can now treat cumulative agreement as resulting from a lack of agreement, rather than from multiple agreement. If there is no agreement in (19), we are dealing with three number features that each have a unique location and each of which must be interpreted. This is unproblematic for the number features in $\mathrm{DP}_{1}$ and $\mathrm{DP}_{2}$. As for the number feature in $\mathrm{V}$, we propose that, in the absence of agreement, plural number marking on a verbal category triggers 
the rule in (20), where $\mathrm{VP}+$ stands for the minimal verbal category that hosts plural number (the contribution of singular is analyzed below as an 'elsewhere' effect). Related proposals can be found in Beavers and Sag 2004 and Chaves 2014.

(20) If $\mathrm{VP}+$ is marked as plural, then $\llbracket \mathrm{VP}+\rrbracket$ holds of a plural individual.

The rule in (20) captures the data discussed above. In (14), the plural marking on the auxiliary implies that have traveled to Cameroon holds of a plural individual. In the multidominance structure, this predicate takes two subjects, which yields the propositions that John has traveled to Cameroon and that Ryo has traveled to Cameroon. If both are true, as assumed in (14), then John and Ryo have traveled to Cameroon, which satisfies (20).

In (16), plural marking on the auxiliary again triggers the requirement that the predicate have traveled to Cameroon applies to a plural individual. However, in this case the two propositions generated under multidominance are not distinct, and so only a singular individual, John, has traveled to Cameroon. Thus, (16) is ill-formed with plural marking - such marking triggers (20) in a context where it is infelicitous.

In (17), two exclusive propositions are at issue, namely 'Ryo has traveled to Cameroon' and 'Carla has traveled to Cameroon.' However, in the context given only one of these is assumed to be true, and therefore it is not possible to conclude that Ryo and Carla have both traveled to Cameroon. Plural marking on the auxiliary is consequently not warranted.

The same logic is relevant in (18a), where plural marking requires that bave stolen the backdoor key applies to a plural individual (presumably John+Ryo). But as the context makes clear, the issue at hand is which of them is the thief, and so plural marking is not appropriate. The example in (18b) comes with a similar interpretive demand, namely that have stolen backdoor keys/a backdoor key applies to a plural individual (again, John+Ryo). However, here the context makes clear that multiple people are indeed assumed to have stolen backdoor keys, so no problem arises. 
The account explains why cumulative agreement is incompatible with disjunction (Beavers and Sag 2004 and Chaves 2014) and why it is blocked by matrix verbs that deny the truth of their complement. The disjunction in (21a) suggests that the vicar and the major have not both committed murder. The matrix verbs in (21b) suggests that no-one has traveled to Cameroon. In neither case, application of (20) is warranted.

(21) a. Poirot will prove that the vicar, or that the major, has/*have committed murder.

b. Mary denies that Ryo, and Susan doubts that John, has/*have traveled to Cameroon.

The set-up so far might seem to render syntactic agreement optional. This is not our intention, however. The rule in (20) is supposed to apply only where syntactic agreement is unavailable. This arrangement is familiar from binding theory. Syntactic binding is often claimed to block variable binding and coreference, which are relations established outside syntax proper (Reinhart 1983, Grodzinsky and Reinhart 1993 and Reuland 2001, 2011). The primacy of agreement over the rule in (20) instantiates the same preference for syntactic rules over non-syntactic alternatives.

Our proposal explains why even where cumulative agreement is licensed, we find an anticollectivity effect: two singular subjects cannot act as a virtual plurality for collective predicates like intransitive meet, as shown in (20) (see Moltmann 1992). Why should this be, given that two singular subjects can act as a virtual plurality for the purposes of number marking?

(22) * Mary is happy that John, and Alma is delighted that Ryo, have finally met.

The solution is straightforward. Application of (20) implies have finally met applies to a plural individual (presumably John+Ryo). However, the structure also encodes that have finally met holds of John and Ryo individually, as these DPs each stand in a predication relation with it. Thus, the predicate must be interpreted distributively: it must be true that John and Ryo have finally met (by virtue of (20)), but also that John has finally met and that Ryo has finally met (by virtue of the syntax). As a collective predicate is not defined when applied to a singular individual, the structure is 
ruled out. ${ }^{5}$

There are two further outstanding matters. The first is whether ATB movement could give rise to cumulative agreement. The evidence suggests a negative answer. Consider the example in (23), where the auxiliary has undergone ATB movement. Even though it c-commands both subjects after movement, it cannot assume a plural form. Given that ellipsis does not license cumulative agreement either, the phenomenon is not just compatible with multidominance, but indicative of it (see footnote 7 for further discussion).

(23) When has/*have [Susan $t_{\text {aux }}$ seen such chaos] and [Helga $t_{\text {aux }}$ heard such cacophony]?

The final outstanding matter has to do with the fact that cumulative agreement is strongly preferred where licensed semantically. Thus, in a context in which multiple people have stolen copies of the backdoor key, the example in (18b) is acceptable, but the one in (24) is clearly degraded.

(24) Several people have stolen backdoor keys, and we know who some of them are.

??Mary discovered that RYO, and Carla discovered that JOHN, has stolen a backdoor key/backdoor keys.

This is expected if the structure is generated through multidominance. The logic of competition has the consequence that where (20) can apply, it must apply - non-application would entail that the predicate applies to a singular individual, or at the very least that the speaker cannot commit to it applying to a plural individual. (The same logic underlies the notion of presupposition maximization in Heim 1991 and Sauerland 2008, a.o.) However, that is not enough to explain the awkwardness of (24). After all, if both conjuncts are realized, the auxiliary appears in the singular:

(25) Mary discovered that RYO has stolen a backdoor key, and Carla discovered that JOHN has stolen a backdoor key.

One would expect singular agreement to survive under ellipsis. That (24) is degraded therefore 
suggests that finite predicates resist elision under RNR. We have no explanation of this apparent fact (although it is unsurprising that RNR-E and RNR-MD have diverging domains of application). As the restriction will play a role below, we state it here as an auxiliary hypothesis:

(26) A finite pivot cannot be created through RNR-E.

The hypothesis in (26) is not without precedents; a very similar constraint holds of forward verbal ellipsis, as shown by the ungrammaticality of the examples in $(27){ }^{6}$

(27) a. *Mary wondered if Ryo had stolen a backdoor key, and Carla questioned whether JOHN $e_{\Gamma}$.

b. *Mary wondered if Ryo had stolen a backdoor key, and Carla also questioned whether $e_{\mathrm{TP}}$. c. *Mary wondered if Ryo had stolen a backdoor key, and Carla also questioned $e_{\mathrm{CP}}$.

We will give two further arguments for (26), one based on prosody (see section 5) and one based on distributional evidence (see section 6).

\section{Multidominance and Scope}

We now investigate why internal readings of relational adjectives should diagnose RNR-MD. Carlson (1987) argues that the availability of an internal reading of same requires distribution over events. John and Ryo read the same book permits an internal reading if John and Ryo each read a book, but not if there is a single event of collaborative book reading. Similarly, an internal reading is possible in John read the same book, twice, but not in John read the same book once. It seems, then, that same must take scope over multiple events to be assigned an internal reading (see Barker 2007 for a reworking of Carlson's insights). This conclusion presumably extends to different.

Now consider (28). If same is to take scope over multiple events, it must take scope over the coordinate structure. Therefore, if internal readings of relational adjectives diagnose RNR$\mathrm{MD}$, multidominance must be a precondition for wide scope of (material within) the pivot. 
(28) Ann read, and Ryo reviewed, the same $\mathrm{INT}_{\text {book. }}$

There is a straightforward explanation for why this should be so. Let us assume that movement cannot create forking chains, that is, a moved category may not c-command two traces that do not themselves stand in a c-command relation:

(29) Movement chains are bijective.

This hypothesis forces a multidominance analysis of ATB movement. The underlying representation in (30a) cannot be transformed into (30b), as (30b) violates the ban on forking chains. (In (30) and below, conjuncts are placed below one another.)

(30) a

$$
\begin{gathered}
\text { Did you } \\
\text { and [give which book to Mary]? }
\end{gathered}
$$
b. [borrow $t_{1}$ from John]
$*[\text { Which book }]_{1}$ did you and [give $t_{1}$ to Mary]?

However, if which book is a multidominated category, $w h$-movement creates a bijective chain, as required (in (31) and below, multidominated categories are placed between conjuncts):

(31) a

$$
\begin{array}{lll}
\text { a. } & \text { fborrow John] } \\
\text { Did you } & \text { which book } & \\
\text { and [give } & \text { to Mary]? }
\end{array}
$$

$\begin{array}{llll}\text { b. [borrow } & \text { from John] } \\ \text { [Which book]1 did you } & t_{1} & \\ \text { and [give to Mary]? }\end{array}$

This is not a new suggestion. It goes back to Williams (1978) and has been developed in varying ways by Goodall (1987), Citko (2005), Muadz (1991), Moltmann (1992) and De Vries (2009). ${ }^{7}$

The ban on forking chains also restricts covert movement from coordinate structures. In particular, it correctly rules out ATB quantifier raising. As pointed out in Bošković and Franks 2000, an example like (32) does not permit a reading in which there is a single universal that takes scope over both conjuncts. The sentence cannot mean that for every book on this shelf it 
is true that either a professor stole it or a student borrowed it. Rather, it means that either all the books were stolen by a professor, or all the books were borrowed by a student.

$$
\begin{aligned}
& \text { [A professor stole } \quad \text { every book on this shelf], } \\
& \text { or [a student borrowed every book on this shelf]. }
\end{aligned}
$$

This observation follows from (29). If every book on this shelf is to undergo ATB quantifier raising to a position outside the coordinate structure, it is inevitable that a forking chain is created:

$*[\text { Every book on this shelf }]_{1}$

$$
\text { [a professor stole } \left.\quad t_{1}\right]
$$

or [a student borrowed $\left.t_{1}\right]$.

Ellipsis cannot be used to solve this problem. It is true that in (34) the number of overt occurrences of every book on this shelf has been reduced to one. However, on the assumption that ellipsis is a PF phenomenon, $e_{\mathrm{VP}}$ contains a second instance of the universal quantifier, and so ATB quantifier raising will still create a forking chain. Hence, (34) cannot mean that for every book on this shelf it is true that a professor or a student stole it.

(34) A professor stole every book on this shelf, or a student did $e_{\mathrm{VP}}$.

This does not mean that quantifiers can never escape coordinate structures. As Ruys (1992:3139) demonstrates, a quantifier may raise out of the first of two VP conjuncts, as long as it binds a category that can act as a variable in the second conjunct (see also Rodman 1976, Reinhart 1987, Fox 2000 and Philip 2012). Thus, there is a sharp contrast between (35a,b) and (35c): only in the former two examples can the universal object take scope over the existential subject.

(35) a. A soldier [found [every traitor $\left.]_{1}\right]$ and $\left[\right.$ shot him $\left._{1}\right]$.

b. A soldier [found [every traitor $\left.]_{1}\right]$ and $\left.[\text { shot [the bastard }]_{1}\right]$.

c. A soldier [found every traitor] and [shot every traitor].

The contrast in (35) follows from (29). In (35a,b), quantifier raising creates a structure in which every traitor binds a single trace (see (36a)), but ATB quantifier raising in (35c) must result in a 
forking chain (see (36b)).

(36) a.

[found $t_{1} \quad$ ],

[Every traitor $]_{1}$ a soldier

and $\left[\operatorname{shot~him}_{1} /[\text { the bastard }]_{1}\right]$.

b. $\quad\left[\right.$ found $\left.t_{1} \quad\right]$,

$*[\text { Every traitor }]_{1}$ a soldier and $\left[\operatorname{shot} t_{1}\right]$.

This brings us back to RNR. Sabbagh (2007) observes that a universal quantifier in examples such as (37) can take scope over the coordination (see also Bachrach and Katzir 2007, 2009). Thus, the example allows a reading in which for every book on this shelf it is true that either a professor stole it, or a student borrowed it - exactly the reading absent in (32) and (34).

(37) A professor stole, or a student borrowed, every book on this shelf.

$\left(\forall>V>\exists_{\mathrm{p}} / \exists_{\mathrm{s}}\right)$

It is easy to see why. On a multidominance analysis, (37) contains only a single instance of every book on this shelf (see (38a)). Hence, if this quantifier raises to a position outside the coordinate structure, the chain created is non-branching and therefore compatible with (29) (see (38b)).

(38) a. [A professor stole or [a student borrowed every book on this shelf

b. $\left[[\text { Every book on this shelf }]_{1}\right.$ [a professor stole or [a student borrowed ].

Note that our account predicts that not only the pivot, but also categories contained in the pivot, can take scope over the coordination. After all, in a multidominance structure material contained within the pivot is represented only once, so that it can move to a position outside the coordination without violating the ban on forking chains. By contrast, quantificational categories represented in multiple conjuncts should be unable to take scope over the coordination, even if part of them functions as the pivot in a multidominance structure. Thus, we correctly predict that the universal in (39a), unlike the one in (39b), can scope over or (that is, only (39a) can express that 
for every theorem that Mary studied, she managed to prove that theorem or managed to disprove it).

(39) a. Mary managed to prove, or she managed to disprove, every theorem she studied.

$(\forall>V)$

b. Mary managed to prove every theorem, or she managed to disprove every theorem, that she studied.

The pattern found with universal quantifiers extends to other scope-taking items. For instance, plural DPs can receive a distributive reading in examples such as (40), presumably through LF raising. On the relevant reading, Ava and Habib will study one Oceanic language each; on the alternative in-situ reading, they will each study multiple Oceanic languages:

(40) Ava and Habib are going to study Oceanic languages.

i. Ava and Habib are each going to study more than one Oceanic language.

ii. Ava and Habib are going to study one Oceanic language each.

That the relevant reading is dependent on LF movement of the plural DP explains its absence in regular coordinate structures (see (41a)), even if the second instance of the DP remains unrealized due to VP ellipsis (see (41b)). Crucially, the distributive reading re-emerges under RNR (see $(41 \mathrm{c}))$.

(41) a. Ava will soon study Oceanic languages and Habib is going to study Oceanic languages, too.

i. Ava and Habib are each going to study more than one Oceanic language.

ii. *Ava and Habib are going to study one Oceanic language each.

b. Ava will soon study Oceanic languages and Habib is going to $e_{\mathrm{vP}}$, too.

i. Ava and Habib are each going to study more than one Oceanic language.

ii. *Ava and Habib are going to study one Oceanic language each. 
c. Ava will soon, and Habib is going to, study Oceanic languages.

i. Ava and Habib are each going to study more than one Oceanic language.

ii. Ava and Habib are going to study one Oceanic language each.

This contrast follows if RNR can result from multidominance. On a multidominance analysis, there is only one instance of Oceanic languages, and so covert movement can take place without creating a branching chain:

(42) a. [Ava will soon and [Habib is going to study Oceanic languages $]$.

b.

[Ava will soon

[Oceanic languages $]_{1}$ and [Habib is going to ].

The pattern extends to internal readings of relational adjectives. In Ann read, and Ryo reviewed, the same book, the relational adjective can assume an internal reading only if the pivot is raised to a position outside the coordinate structure. Hence, by (29) there must be a single instantiation of the same book prior to movement. This is the case on a multidominance analysis (see (43)), but not under ellipsis. Thus, relational adjectives can be used to diagnose multidominance.

(43) a. [Ann read and [Ryo reviewed ${ }^{\text {the same book }}$ ].

b. [The same book $]_{1}$ [Ann read $\left.\quad \mathrm{t}_{1}\right]$ and [Ryo reviewed ].

While an ellipsis analysis of RNR cannot explain the scope data, it is less clear whether a movement analysis (without multidominance) can do so. If one adopts the ban on forking movement chains, it follows that ATB movement out of coordinate structures is impossible. Hence, RNR cannot be analyzed as movement to begin with. If the ban on forking chains is rejected, RNR can be analyzed as ATB movement. Such movement would place the pivot in a position c-commanding the coordinate structure, so that the scopal properties of the construction follow. 
However, with a rejection of the ban on forking chains it becomes unclear how ATB quantifier raising can be ruled out (and so the contrast between $(35 \mathrm{a}, \mathrm{b})$ and $(35 \mathrm{c})$ remains mysterious). Of course, this issue can be tackled by reinstating the ban on forking chains and assuming that ATB movement requires multidominance. But if so, a movement account of RNR would have to start out from a multidominance structure, too. This implies that ATB movement can no longer be seen as an alternative for multidominance, but only as an addition. We conclude that a unitary movement analysis (i.e. an analysis that does not employ multidominance) cannot capture the scopal properties of RNR. Thus, we may complete table I as follows: ${ }^{8}$

\begin{tabular}{lcccccc}
\hline & Movement & Ellipsis & M-dominance & $\begin{array}{c}\text { Movement } \\
\text { + ellipsis }\end{array}$ & $\begin{array}{c}\text { Movement }+ \\
\text { m-dominance }\end{array}$ & $\begin{array}{c}\text { Ellipsis + } \\
\text { m-dominance }\end{array}$ \\
\hline a. Order preservation & X & $\checkmark$ & $\checkmark$ & $\times$ & $\times$ & $\checkmark$ \\
b. Island insensitivity & $\times$ & $\checkmark$ & $\checkmark$ & $\checkmark$ & $\checkmark$ & $\checkmark$ \\
c. Non-rebracketing & $\times$ & $\checkmark$ & $\checkmark$ & $\times$ & $\times$ & $\checkmark$ \\
\hline d. Mismatches & $\times$ & $\checkmark$ & $\times$ & $\checkmark$ & $\times$ & $\checkmark$ \\
e. Vehicle change & $\times$ & $\checkmark$ & $\times$ & $\checkmark$ & $\times$ & $\checkmark$ \\
\hline f. Internal readings & $\times$ & $\times$ & $\checkmark$ & $\times$ & $\checkmark$ & $\checkmark$ \\
g. Cumulative Agr. & $\times$ & $\times$ & $\checkmark$ & $\times$ & $\checkmark$ & $\checkmark$
\end{tabular}

Table II: Overview of the empirical coverage of unitary and dual analyses

On the dual analysis we advocate, RNR does not place the pivot outside the coordinate structure; RNR merely facilitates ATB quantifier raising out of a coordinate structure. This leads to a further prediction. If the pivot is contained in an island, internal readings of relational adjectives should no longer be licensed. Abels (2004) argues that this is indeed the case. He shows that relational adjectives can scope quite high but are bounded by wh-questions (see (44a)). In line with this, an internal reading of different is excluded in the RNR construction in (44b). 
(44) a. [My friend Konrad is wondering when Bob Dylan wrote his song Mister Tambourine Man and my friend Friederike would like to know when Bob Dylan wrote his song The Times They Are a-Changin'.]

*?Konrad and Friederike are wondering when Bob Dylan wrote two quite different songs.

b. [My friend Konrad has written a song called Revolution \#10 and my friend Friederike has recorded a song called Revolution \#11. Despite bearing similar titles, the two songs are quite different from each other. I would like to know when Konrad wrote his Revolution \#10 and you would like to find out when Friederike recorded Revolution \#11.

Revolution \#10 is the only song Konrad ever wrote and Revolution \#11 the only song Friederike ever recorded.]

*? I wonder when Konrad wrote, and you would like to know when Friederike recorded, two quite different songs.

This is further evidence that a unitary movement analysis cannot capture the scopal properties of RNR. Given the grammaticality of (4a), ATB movement out of $w h$-questions would have to be permitted. But if it is permitted, the ungrammaticality of the examples in (44) is unexpected.

\section{Possible and Impossible Interactions}

We have argued that RNR has two instantiations: RNR-E and RNR-MD. In this section we consider possible and impossible interactions between these processes. Barros and Vicente (2011) argue that in any given structure RNR should be ellipsis or multidominance, but not both. Therefore, the tests that diagnose ellipsis (mismatches and vehicle change) and the tests that diagnose multidominance (wide scope and cumulative agreement) should not simultaneously give positive results. For this reason, the data in Larson 2012 are often taken to refute Barros and Vicente's account - they show mixed patterns. Now, it is true that within a pivot created through multidominance we would not expect to find indicators of ellipsis. The reverse, however, should 
be possible. A RNR structure created through ellipsis could conceivably have a pivot containing a secondary pivot created through multidominance. This secondary pivot (ZP in (45)) would simultaneously function as part of the elided constituent and as part of the primary pivot (YP in (45)):

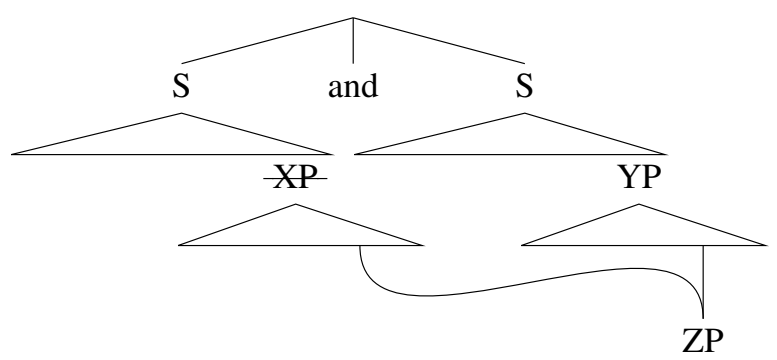

In other words, (46) is one possible analysis of Ava will, and Habib is going to study, the same Oceanic language, with the two VPs corresponding to XP and YP in (45), and the DP corresponding to ZP.

(46) [Ava will [vp study and [Habib is going to [vp study [Dp the same Oceanic language] ]. There are two possible objections to (45). The first is that the multidominated category ZP in (45) is pronounced, yet part of XP, a category that is elided. (As (7b) shows, it is not possible to combine RNR with VP ellipsis in a similar way.) Whether this objection holds water depends on the way multidominance structures are linearized. For now, notice that the multidominated category is realized within the pivot, not within the elided category. This, presumably, is what saves the structure from ungrammaticality. We return to the issue in section 7.

A second possible objection to (45) is that it requires more than one application of RNR: part of a pivot created through RNR-E is itself a pivot created through multidominance. But this does not disqualify (45), as there are other structures that can only be generated if RNR is applied more than once (Grosu 1976 and Abbott 1976). An example is given in (47). Since John and excessively do not form a constituent, the only plausible analysis of (47) is as a case of repeated RNR. Hence, one cannot object to (45) on the basis that it, too, requires multiple applications of 
RNR.

(47) Mary flattered, and Bill disparaged, John excessively.

From the above, a linear constraint on mixed patterns can be derived. It is uncontroversial that RNR is subject to a constraint that the raised category must be rightmost within the first conjunct. Suppose that this constraint extends to pivot-internal RNR (an assumption we revisit in section 7 , where we discuss matters of linearization). Then we may conclude that the secondary pivot must be rightmost within the primary pivot, as in (48a), where YP is the primary pivot (after elision of XP) and ZP the secondary pivot (through multidominance). If some element $\beta$ followed ZP in YP and a corresponding element $\alpha$ followed ZP in XP, as in (48b), then the structure would be ruled out: ZP would undergo RNR without being rightmost in the first conjunct.
a. $\left[\begin{array}{llllll}\mathrm{s} & \cdots & {[\mathrm{XP}} & \ldots & \alpha & \end{array}\right]$ ZP and $\left[\begin{array}{llllll}\mathrm{s} & \ldots & {[\mathrm{YP}} & \ldots & \beta & ]\end{array}\right]$.
b. ${ }^{*}\left[\begin{array}{lllll}s & \cdots & {[\mathrm{xp}} & \ldots & \alpha\end{array}\right]$ ]. and $\left[\begin{array}{llllll}s & \ldots & {[\mathrm{YP}} & \ldots & \mathrm{ZP} & \\ & & & \beta\end{array}\right]$.

Properties indicative of multidominance (PIM) may be found within ZP. For an element within YP to exhibit properties indicative of ellipsis (PIE), that element must be paired with a corresponding element in XP. As we have just shown, there can only be a pair $\langle\alpha, \beta>$ of corresponding elements if $\alpha$ and $\beta$ each precede ZP. Consequently, no category with PIE can follow a category with PIM:

$$
[\text { primary pinot } \ldots<\operatorname{PIE}>\ldots[\operatorname{secondary~pivot~} \ldots \text { PIM } \ldots] \ldots<* \operatorname{PIE}>\ldots]
$$

Thus, the predicted pattern of interactions is more subtle than Barros and Vicente suggest. A pivot may exhibit both PIE and PIM, but only if the constituent displaying the former precedes the constituent with the latter. The discussion below shows that the data bear out this prediction.

Most of the tests we will employ are familiar. To diagnose ellipsis, we make use of morphological mismatches and vehicle change. To diagnose multidominance, we make use of inter- 
pretational effects that depend on (part of) the pivot taking wide scope. We also rely on the auxiliary hypothesis in (26), according to which a finite predicate cannot act as a pivot created by ellipsis. This hypothesis was posited to explain why cumulative agreement is strongly preferred where semantically licensed.

There is a further prediction to be made regarding the prosody in mixed cases. As it turns out, examples such as (47) can be pronounced with a prosodic break preceding either the first or the second pivot (see (50)). The prediction in the mixed cases we are interested in - where a secondary RNR-MD pivot is contained within a RNR-E pivot - is more subtle. As noted in section 2, pivots created by multidominance differ from those created by ellipsis in that the former require a pre-pivotal prosodic break, while in the latter case the preference is for no pre-pivotal break. This means that in structures with PIE-PIM order, we expect the preferred position of the pre-pivotal break to occur within (rather than preceding) the primary, RNR-E, pivot, at the onset of the secondary, RNR-MD, pivot. (Structures with PIM-PIE order are predicted to be ungrammatical, irrespective of prosody.)

(50) Mary FLATTERED, and Bill DISPARAGED <\#> John <\#> excessively.

The test just described provides additional evidence for the hypothesis that a finite predicate cannot act as a pivot created by ellipsis. To begin with, consider (51). Here, the pivot is a non-finite predicate; it can have been created though elision in the left conjunct or through multidomination. On the ellipsis analysis, a second instance of RNR is necessary, given that the pivot ends in a PP containing a relational adjective that has an internal reading. Hence, either the VP or the PP must be a multidominated category. This explains why the prosodic break preferentially shifts rightward, appearing either before the auxiliary, or before the main verb, or before the to-PP:

(51) Mary is proud that she WILL, and Alma is glad that she COULD, $<\#>$ [Auxp have $<\#>$ [vp traveled $<\#>\left[\right.$ pp to the same ${ }_{\mathrm{INT}}$ country]]].

The example in (51) contrasts with the one in (52), where the pivot is a finite predicate. Given 
(26), we must hence be dealing with RNR-MD, something that makes it impossible for a second application of RNR to affect subparts of the pivot. As a result, it is predicted - correctly - that the prosodic break in (52) cannot shift rightward.

(52) Mary is proud that JOHN, and Alma is glad that RYO, $<\#>[$ T , will $<* \#>$ [vp travel $<* \#>[$ pp to the same INT $_{\text {country]]]. }}$

We now move to the main point of the section - the predicted contrast between PIE-PIM and PIM-PIE orders. Our first step is to establish that the primary pivot can exhibit PIE, while a rightperipheral secondary pivot displays PIM. We use the example in (53) as a baseline. As will be selects studying and going to selects study, the example contains a morphological mismatch typical of ellipsis.

(53) Habib is going to, and Ava will soon be, studying Eastern Fijian.

We have identified three interpretive effects that rely on (part of) the pivot raising out of the coordinate structure at LF, a movement that requires multidominance. The first was a distributive reading of plural DPs (see (41) above). If the structure in (46) exists, the example in (54) can be analyzed with VP a pivot created through RNR-E and the plural DP contained within it a pivot created through RNR-MD. It is therefore predicted that (54) has a reading on which Ava and Habib will study one Oceanic language each. That reading indeed exists.

(54) Habib is going to, and Ava will soon be [vp studying, [Dp Oceanic languages]].

i. Ava and Habib are going to study one Oceanic language each.

ii. Ava and Habib are each going to study more than one Oceanic language.

If this mixing of properties is indeed a consequence of repeated RNR, as in (42), we predict that the prosodic break that precedes the pivot can shift rightward to immediately before the DP. This, too, is correct: the most natural intonation of (54) is as indicated in (55).

(55) Habib is GOING to, and Ava will SOON be [vp studying \# [DP Oceanic languages]]. 
These observations extend to examples in which the property indicative of multidominance is a universal taking wide scope over the coordinate structure, as in (56), or a relational adjective with an internal reading, as in (57). The relevant interpretations are available despite the pivot giving rise to a morphological mismatch. As expected, the preferred intonation shifts the second prosodic break rightwards: ${ }^{9}$

(56) Mary MANAGED to, or made PROGRESS in [vp proving \# [DP every theorem that she studied]] $(\mathrm{V}>\forall ; \forall>\mathrm{V})$

(57) Habib is GOING to, and Ava will SOON be [vp studying \# [DP the same $\mathrm{INT}_{\mathrm{T}}$ Oceanic language]]. A further instantiation of PIE-PIM order is given in (58). Here, the property indicative of ellipsis is vehicle change. She and Ava are to be read as coreferential, which implies that the constituent labeled VP must be a pivot created by RNR-E (with $A v a$ 's in the left conjunct replaced by her). Because of the availability of the structure in (45), it is still possible for the direct object to be a (right-peripheral) secondary pivot created through RNR-MD. This allows it to undergo LF raising, so that the relational adjective it contains can have an internal reading. As predicted, the prepivotal break shifts rightward to immediately before the direct object.

(58) Ava has been asked by her supervisor if she or anyone else she knows has come across any interesting papers on Niuean. So, she askes her fellow students. So now it turns out that...

She ${ }_{1}$ is GOING to, and Ryo will SOON [vp show Ava 1 's supervisor \# [DP the same INT $_{\text {T }}$ paper on Niuean word order]].

The same pattern obtains when the property indicative of multidominance is the distributive interpretation of a plural DP. As (59) shows, a right-peripheral plural direct object contained in the pivot can be interpreted distributively, even if the indirect object is involved in vehicle change. Again, a rightward shift of the pre-pivotal prosodic break is preferred. 
(59) Ava's supervisor is interested in reading any papers on Niuean word order. Actually, she and Ryo have both been working on the subject. So now ...

She $_{1}$ is GOING to, and Ryo will SOON [vp show Ava1's supervisor \# [DP their papers on Niuean word order]].

i. Ava and Ryo are each going to show more than one paper.

ii. Ava and Ryo are going to show one paper each.

We conclude that there is an abundance of evidence for the acceptability of PIE-PIM orders and consequently for the reality of the representation in (45).

We now turn to PIM-PIE orders, which are predicted to be ungrammatical. It is not possible for material contained in a primary pivot created through RNR-E to follow a secondary pivot created through RNR-MD. Therefore, any element exhibiting properties indicative of ellipsis must precede any element exhibiting properties indicative of multidominance. One observation confirming this prediction is that a variant of (58) in which the R-expression and the relational adjective appear in reverse order does not permit an internal reading of the adjective:

(60) Ava has written a new paper, but she's not at all confident it's any good. So, we've been trying to persuade her to show it to someone. So now it turns out that...

*?She ${ }_{1}$ is going to, and Ryo will soon, [vp show the same $\mathrm{INT}_{\mathrm{NT}}$ person [DP Ava1's paper on Niuean word order]].

The example in (60) is grammatical if she and $A v a$ are taken to be coreferential, but the adjective receives an external reading (so that the person that Ava is going to show her paper to is the same as the person she showed her paper to before, and the person that Ryo is going to show Ava's paper to is the same as the person he showed her paper to before). It is also grammatical on an internal reading of the adjective if she and $A v a$ are not taken to be coreferential (so that an unidentified woman will show Ava's paper to the same person that Ryo will show Ava's paper to). (As expected, these readings require a context different from the one in (60)). 
The second prosodic break cannot shift rightward in (61). This is because the internal reading of the relational adjective implies that the indirect object and everything to its right must be part of a pivot created through multidominance. Within pivots created through multidominance there cannot be secondary pivots, and so there is no trigger for a shift of the prosodic break. ${ }^{10}$

(61) Mary is GOING to, and Ryo will SOON <\#> [vp show the same INT $_{\text {T }}$ person $<* \#>$ [Dp Ava's paper on Niuean word order]].

The ungrammaticality of the PIM-PIE order is further confirmed by (62), where the plural indirect object cannot receive a distributive interpretation if she and $A v a$ are taken to be coreferential (compare (59)). (Recall that a distributive reading of plural DPs is a property indicative of multidominance, while vehicle change is a property indicative of ellipsis.)

(62) Ava and Ryo's supervisors are looking for any new papers on Niuean. Actually it turns out that Ava has written one. So...

She ${ }_{1}$ is going to, and Ryo will soon, [vp show their supervisors [Dp Ava's paper on Niuean word order]].

i. Ava and Ryo are each going to show Ava's paper to more than one supervisor.

ii. *?Ava and Ryo are going to show Ava's paper to one supervisor each.

As indicated, the example is grammatical if their supervisors does not receive a distributive interpretation. It is also grammatical if their supervisors receives a distributive interpretation, but she and Ava are not taken to be coreferential, so that Ryo and an unidentified woman are going to show Ava's paper to one supervisor each. (These readings require contexts different from those in (62).)

The prosody confirms that pivot-internal RNR of the direct object is impossible when the indirect object receives a distributive reading: 
(63) Mary is GOING to, and Ryo will SOON $<\#>$ [vp show [Dp their supervisors] $]_{\mathrm{DIST}}<* \#>$ [DP Ava's paper on Niuean word order]].

Another way in which we can demonstrate that PIM-PIE orders are ungrammatical is by using examples in which the pivot is a finite predicate. The auxiliary hypothesis in (26) requires that such pivots are created through RNR-MD. Hence, we predict that properties indicative of ellipsis cannot follow a finite verb or auxiliary and are therefore excluded from finite pivots altogether.

This prediction is correct. To begin with, an example like (64) does not permit the vehicle change necessary to circumvent a principle $\mathrm{C}$ violation. ${ }^{11}$

(64) Everyone in Claire's family is hopeless in any kind of leadership position - even she recognizes that! But...

*?She ${ }_{1}$ fears that Alex, and I worry that Bob, have decided to nominate Claire,'s brother.

This example can usefully be compared with those in (65a) and (65b) (in the same context). The former is predicted to be grammatical. It does require vehicle change, but this is unproblematic, given that the pivot is not a finite predicate. The example in $(65 \mathrm{~b})$ is also predicted to be grammatical. Here, the pivot is a finite predicate, but the potential principle $\mathrm{C}$ violation has been removed.

(65) a. She ${ }_{1}$ fears that Alex has, and I worry that Bob has decided to nominate Claire,'s brother.

b. She ${ }_{1}$ fears that Alex, and I worry that Bob, have decided to nominate her ${ }_{1}$ brother. $^{2}$

Recall that we have already demonstrated that the pre-pivotal prosodic break cannot shift rightward into a finite predicate (see (52)).

It is also impossible to have material that gives rise to a morphological mismatch internally to a pivot that is a finite predicate. In (66), the mismatch is induced by the possessive pronoun their, which cannot appear in the first conjunct (cf. *We have given Daniel a piece of their $\min d)^{12}$ 
(66) *?Claire is delighted that we, and Ava is glad that his parents, have given Daniel a piece of their mind.

As expected, the example becomes grammatical when the morphology of the pronoun is compatible with the antecedent in the first conjunct (see (67a)), or when finiteness is removed from the predicate that acts as the pivot (see (67b)).

(67) a. Claire is delighted that his teachers, and Ava is glad that his parents, have given Daniel a piece of their mind.

b. Claire is delighted that we have, and Ava is glad that his parents have given Daniel a piece of their mind.

In sum, PIM-PIE orders are consistently degraded while PIE-PIM orders are acceptable. Although this pattern of interaction is not what Barros and Vicente (2011) argue for, it is in fact predicted by a dual ellipsis-plus-multidominance account. Given standard linear constraints on RNR, a secondary pivot must be right-peripheral within the primary pivot. As the primary pivot is created through ellipsis and the secondary pivot through multidominance, elements exhibiting properties indicative of ellipsis must precede elements displaying properties indicative of multidominance.

\section{Coordinate Closure Only}

There is one type of evidence for a dual account of RNR that we have not explored sufficiently. Circumstances may exist in which one of the analyses normally available is ruled out, so that RNR displays only properties compatible with the remaining analysis. We have already seen that when the pivot is a finite predicate, RNR must be multidominance, so that neither morphological mismatches nor vehicle change are tolerated. In this section, we argue that the opposite pattern is found with RNR in non-coordinate structures. As it turns out, RNR in non-coordinate structures must be ellipsis, with the consequence that evidence for multidominance disappears.

Our starting point is the observation in Hudson 1976 that RNR is not exclusive to coordinate structures. Thus, alongside (68a), we find examples such as (68b). 
(68) a. I met a man who likes, and a woman who dislikes opera.

b. A man who likes, met a woman who dislikes opera.

Although the existence of RNR in non-coordinate structures is generally acknowledged, its properties are not widely discussed. We believe that it differs from RNR in coordinate structures in displaying PIE, but not PIM. In particular, we do not find the exceptional wide-scope phenomena typical of RNR-MD pivots. Thus, the plural DP in (69) cannot receive the distributive reading in (ii), but must be interpreted as in (i).

(69) I gave a book about, to a die-hard fan of, two rather dull subjects.

i. 'I gave a book about two rather dull subjects to a die-hard fan of two rather dull subjects.'

ii. *'I gave a book about one rather dull subject to a die-hard fan of another rather dull subject.'

This follows if the structure must involve ellipsis. On an ellipsis analysis, the DP and PP complements each contain an instance of two rather dull subjects. Consequently, LF raising cannot take place without creating a forking chain, contra (29). The same logic correctly rules out an internal reading of the relational adjective in (70a) and a construal of (70b) with the universal taking wide scope.

(70) a. *I gave a book about, to a die-hard fan of, the same INT subject.

b. I gave a book about, to a die-hard fan of, every American president.

$$
\left(\exists_{\text {book }} / \exists_{\text {fan }}>\forall, * \forall>\exists_{\text {book }} / \exists_{\text {fan }}\right)
$$

A further piece of evidence that suggests that RNR-MD is unavailable outside coordinate structures comes from the distribution of finite pivots. The example in (71a) is clearly ungrammatical. One may attribute this to the fact that have carries cumulative agreement (which is indeed a property indicative of multidominance). However, if the auxiliary hypothesis in (26) is correct, we expect the effect to be more general, as that hypothesis asserts that ellipsis can never create a finite pivot. Indeed, (71) is decidedly odd (and gets worse the longer one contemplates its status). 
(71) a. *A man whose daughter, met a woman whose son, have traveled to Cameroon.

b. ??A man whose daughter, met a woman whose son, has traveled to Cameroon.

Thus, RNR in non-coordinate structures lacks properties indicative of multidominance. It does, however, allow morphological mismatches and vehicle change. In (72a), going to selects an infinitive, while be selects a progressive. In (72b), Ava's must be replaced by a possessive pronoun in the first relative clause. Mismatches and vehicle change are, of course, tell-tale signs of ellipsis.

(72) a. A man who is going to, married a woman who will soon be studying Niuean grammar.

b. Ava is worried that a critical response to her work is in preparation.

A man who she 1 said is going to, met a woman who will soon study Ava's paper on Niuean word order.

Why should it be that RNR outside coordinate structures cannot be the result of mul-

tidominance? We speculate that the explanation lies in the way multidominated categories are interpreted. Consider an example like Father McKenzie married a man who likes, and a woman who dislikes, opera, on the assumption that opera is the object of both likes and of dislikes. The minimum that must be true is that opera, once interpreted, combines with $\lambda y \lambda x \cdot \operatorname{likes}\left(x_{2} y\right)$ and $\lambda y \lambda x$.dislikes $(x, y)$, yielding $\lambda x \cdot \operatorname{likes}(x$, opera $)$ and $\lambda x \cdot \operatorname{dislikes}(x$, opera $)$. If this is all that is assumed, multidominance is simply undone at LF: it has no semantic import. We do not think that this is correct. In general, syntactic connections trigger semantic connections, and we take it that the same must be true of multidominance.

The difficulty is that regular composition operates on categories that are sister nodes in the syntax. As will be clear, the VPs in which opera appears are not structural sisters. This means that any relation between them must be established by an operator that can be inserted by default in the absence of a morpho-syntactic element that triggers composition. We assume that the relevant operator, which we will label $C$, forms tuples that are interpreted conjunctively or 
disjunctively depending on context. ( $C$ may also be responsible for the interpretation of coordinate structures, which are analyzed as resulting from merger without selection in Neeleman, Philip, Tanaka and Van de Koot 2021. An analysis along these lines implies that coordinators like and and or do not introduce the coordinate interpretation, but rather disambiguate between the readings permitted by $C$, thus explaining the possibility of asyndetic coordination).

Since the insertion of $C$ is triggered by a connection at the bottom of the tree, it is not dictated by the syntax which categories will end up as its arguments. We assume that $C$ may in principle apply to any two (or more) categories that share the multidominated category. As there is no existing notation for this kind of semantic commitment, we will place $C$ s arguments in boxes, as in (73) (where semantic material appears in small capitals). What (73) is intended to say is that $C$ takes as its arguments a semantic representation that contains or is identical to LIKES OPERA and a semantic representation that contains or is identical to DISLIKES OPERA.

(73) C(LIKES OPERA, DISLIKES OPERA)

Further interpretation of the example under consideration leads to (74).

(74) C A MAN WHO LIKES OPERA, A WOMAN WHO DISLIKES OPERA

The next element to be integrated is the coordinator and. At this point, the interpretation of $C$ can be disambiguated, as in (75) (further interpretation of the example is trivial and will be ignored).

(75) AND(A MAN WHO LIKES OPERA, A WOMAN WHO DISLIKES OPERA)

An immediate implication of this procedure is that, in the absence of coordination, RNR cannot involve multidominance. Consider $A$ man who likes, married a woman who dislikes, opera. On a multidominance analysis, the interpretation of this example would require insertion of $C$ (given that opera is the object of both likes and dislikes. But once a commitment to coordination is introduced, integrating married is impossible. The transition from (74) to (76) is illicit, as the relation 
expressed by married is not an instance of coordination.

(76) MARRIED (A MAN WHO LIKES OPERA, A WOMAN WHO DISLIKES OPERA)

It is a direct consequence of this account that RNR-E, which does not involve multidominance and therefore does not require insertion of $C$, is not restricted to coordinate structures.

Independent support for the hypothesis that multidominance triggers insertion of $C$ comes from Horn amalgams. This construction was first discussed by Lakoff (1974) and attributed by him to Larry Horn. An example is given in (77). Van Riemsdijk $(1998,2006)$ argues that Horn amalgams consist of a host sentence and a qualifying sentence that share a constituent (which we call the pivot, on a par with the multidominated category in RNR). Subsequent work by Guimarães (2004) and Kluck (2008) shows that in many cases the qualifying sentence contains an it cleft reduced through sluicing. On this view, (77) is assigned the structure in (78):

(77) John is going to, I think it's Chicago on Saturday.

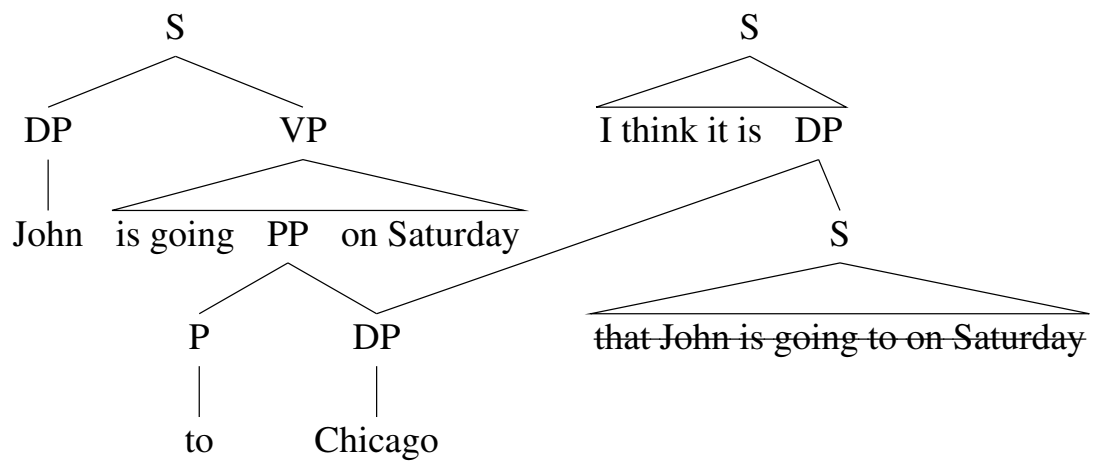

The multirooted multidominance analysis of Horn amalgams is well motivated. Van Riemsdijk shows, using morphological case in German, that the pivot must meet inflectional demands imposed on it by the host sentence, as well as by the qualifying sentence. The resulting obligatory match of inflectional requirements is predicted if the pivot is a multidominated category. Van Riemsdijk also demonstrates that the structure of the qualifying sentence is invisible for operations in the host sentence, as expected if there is no embedding. Kluck (2008) adds to this that 
the host and qualifying sentences behave like independent root domains. For instance, the qualifying sentence, with the exception of the pivot, is not in the scope of operators in the host sentence. These facts follow if the host and qualifying sentences have undominated root nodes.

We now consider the interpretation of Horn amalgams, and specifically the question of how the host and qualifying sentences are related. First, consider the example in (79). A speaker who utters (79) is committed to the truth of the host, as well as the qualifying sentence.

(79) John is going to, I'm sorry to say it's Chicago on Saturday.

This interpretation is trivially compatible with our claim that multidominance triggers the introduction of $C$. In the case at hand, $C$ would have to assume a conjunctive interpretation:

(80) CDOHN IS GOING TO CHICAGO ON SATURDAY, I AM SORRY TO SAY THAT IT IS CHICAGO THAT JOHN IS GOING TO ON SATURDAY

The more interesting case involves Horn amalgams in which the qualifying sentence introduces a hedge. For example, (77) implies that if John is not going to Chicago, then at least he is going to a city that the speaker thinks is Chicago. This is also compatible with the claim that multidominance triggers insertion of $C$, but here $C$ must be interpreted disjunctively:

(81) C(JOHN IS GOING TO CHICAGO ON SATURDAY, I THINK THAT IT IS CHICAGO THAT JOHN IS GOING TO ON SATURDAY)

If one honestly asserts that John is going to Chicago on Saturday, then one must think that the city that John is going to on Saturday is Chicago. However, if one merely thinks that the city that John is going to on Saturday is Chicago, then one is not able to assert that John is going to Chicago on Saturday. Therefore, for (81) to make sense, the speaker must commit to the assertion in the second conjunct, but not to the one in the first conjunct. This is possible if the relation between the two clauses is disjunctive. The hedging effect of Horn amalgams now falls into place.

This account solves a problem identified in Kluck 2008. In standard multidominance 
analyses of Horn amalgams, the host sentence and the qualifying sentence are semantically independent assertions, which means that a speaker who utters (77) should commit to the truth of both. But that implies that the speaker must commit to the claim that John is in fact going to Chicago - in other words, the hedging effect typical of Horn amalgams remains unexplained.

Horn amalgams do not permit non-coordinate interpretations. To see this, consider (82), which is acceptable as a hedged statement on the reading in (82a). Potentially, there are perfectly reasonable alternative interpretations of the example, however. For instance, it could be that John must leave for Chicago because Susan said he should go there (that is, Susan has ordered John to go to Chicago). Or it could be that Susan said that John must leave for Chicago because John must in fact leave for Chicago (that is, Susan reports that John must leave for Chicago). Both readings are clearly absent, which demonstrates that Horn amalgams cannot be interpreted causally.

(82) John must leave for, Susan said it is Chicago.

a. 'John must leave for Chicago, or Susan said it is Chicago that he must leave for.'

b. *'John must leave for Chicago, because Susan said it is Chicago that he must leave for.'

c. *'John must leave for Chicago, so Susan said it is Chicago that he must leave for.'

Similarly, Horn amalgams do not allow a temporal relation between the main clause and the qualifying clause. The example in (83) can be interpreted as the hedged statement in (83a), but the two temporal interpretations in (83b) and (83c) are not available. (These interpretations may seem odd at first sight, but they are feasible if the speaker is planning a hoax involving John.)

(83) John must leave for, I hear it is Chicago.

a. 'John must leave for Chicago, or I hear it is Chicago that he must leave for.'

b. *'John must leave for Chicago, before I hear it is Chicago that he must leave for.'

c. *'John must leave for Chicago, after I hear it is Chicago that he must leave for.'

Thus, like RNR structures created through multidominance, Horn amalgams are licit if the two 
structures in which the pivot appears are semantically connected through coordination. In the absence of such an interpretation, both structures are ruled out.

We close this section with some brief remarks on multidominance as an analytical tool. Over the past two decades, multidominance has been used to account for a bewildering set of phenomena, ranging from movement (Starke 2001 and Gärtner 2002) to serial verb constructions (Hiraiwa and Bodomo 2008), from gapping (Kasai 2007 and Citko 2011) to free relatives (Van Riemsdijk 1998, 2000, 2006), and from parentheticals (De Vries 2005) to parasitic gaps (Kasai 2007). If these proposals are all correct, we end up with a theory in which phenomena analyzed in terms of multidominance have very different properties.

The above suggest that multidominance is less widespread than the literature has it. Multidominance structures either are multi-rooted (as in the case of Horn amalgams) or they are single-rooted coordinations. If so, various phenomena accounted for through multidominance can no longer be analyzed in this way. Chief among these is movement. If movement were a singlerooted multidominance structure, it would have to be a coordination, which is clearly incorrect.

It is striking that a theory permitting multidominance should rule out a multidominance account of movement, given the prominence of the multidominance theory of movement (Starke 2001 and Gärtner 2002). However, the hypothesis that movement is multidominance already faced difficulties (see Neeleman and Van de Koot 2010). It may well be, then, that the proposed link between coordination and multidominance makes the right cut.

\section{The Unity of Right-Node Raising}

In the preceding sections we have made our case for a dual analysis of RNR, arguing that the construction results from either ellipsis or multidominance. The case was based on three types of evidence. First, RNR displays both PIE and PIM. Second, our account correctly predicts a striking pattern of interaction between PIE and PIM (PIE-PIM; *PIM-PIE). Third, there are specific circumstances under which either RNR-E or RNR-MD is ruled out, so that RNR behaves as pure multidominance or pure ellipsis. Pure multidominance is found when the pivot is finite. Pure ellipsis 
is found outside coordinate structures.

While these considerations provide evidence for a dual account of RNR, they also prompt an urgent question. If RNR is two things, why should it give the impression of being one? In particular, why should RNR-E and RNR-MD be subject to the same word order restrictions? While this question is pertinent to all dual accounts of RNR, it is not answered in Barros and Vicente 2011, Valmala 2013, Chaves 2014 or Hirsch and Wagner 2015. The aim of this section is to develop an explanation of the observed unitary behavior in terms of the PF interface. The proposal is based on insights already present in Wilder's (1999) work on the linearization of multidominance structures (see also Bachrach and Katzir 2007, 2009).

It is clear that multidominance creates a problem for linearization. The problem lies in the no-tangling condition (Partee et al. 1993:437): the ban on crossing branches in linearization. If opera in (84) is realized as part of the second conjunct, as in (84a), the branch labeled 4 will cross branches 5 and 7. If it is realized as part of the first conjunct, as in (84b), then branches 5 and 7 will again be crossed, this time by branch 8 . Thus, there is no grammatical linearization of the structure.

(84) a.

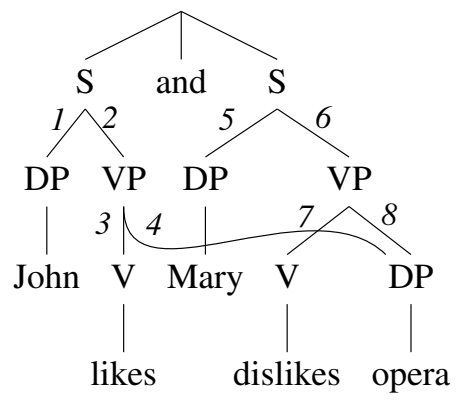

b.

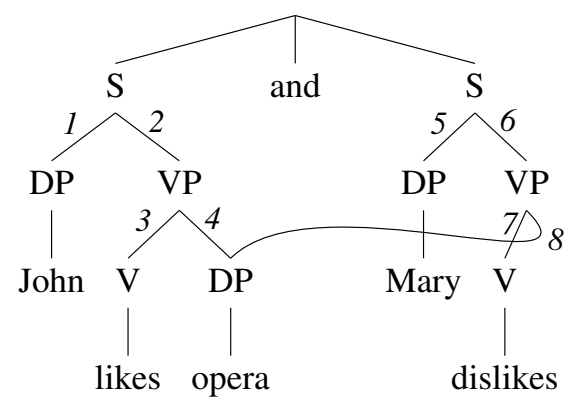

We propose that the grammar deals with this difficulty through a pruning operation which, in the case at hand, removes branch 4. It thus delivers (85) if given (84) as input. 
(85)

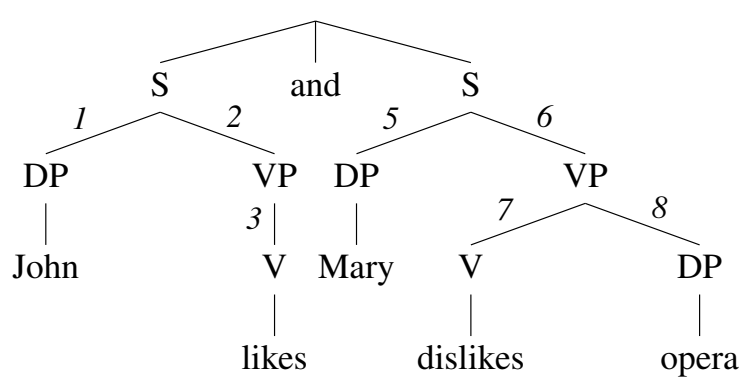

It goes without saying that pruning cannot be unrestricted. If any structure that violates the notangling condition could be repaired, it would be impossible to capture the empirical profile of RNR. We therefore assume the specific pruning operation defined in (86) (see also Vicente 2009). ${ }^{13}$

(86) Let $S_{\alpha}$ and $S_{\beta}$ be parallel structures. A branch $\alpha$ in $S_{\alpha}$ may be pruned if (i) $S_{\alpha}$ precedes $S_{\beta}$, (ii) $\alpha$ corresponds to a branch $\beta$ in $S_{\beta}$, and (iii) $\beta$ 's yield satisfies the ordering statements that hold of $\alpha$ 's yield in $\mathrm{S}_{\alpha}$.

The condition in (86i) rules out left node raising. (86ii) relies on the traditional notion that conjunction reduction requires parallelism between the domain that - in descriptive terms - contains the gap (the 'dependent domain') and the domain that contains the antecedent (the 'antecedent domain') (see Williams 1978, Goodall 1987, Moltmann 1992 and Hartmann 2000). We adopt Hartmann's (2000:117) definition of parallel clauses, which is given in (87). According to this definition, which is rooted in Rooth's (1992) alternative semantics, two clauses are parallel if the ordinary value of the first is an element of the focus value of the second, and vice versa. The implication is that parallel clauses must be (roughly) isomorphic in terms of their syntax and information-structure. This, in turn, makes it possible to identify corresponding branches.

(87) $A$ and $B$ are parallel clauses iff $\llbracket A \rrbracket_{\circ} \in \llbracket B \rrbracket_{f} \wedge \llbracket B \rrbracket_{\circ} \in \llbracket A \rrbracket_{f}$.

The condition in (86iii) states that pruning is only possible if the pivot meets ordering statements associated with the pruned branch in the dependent domain (so that the branch pointing to the pivot is a proxy for the pruned branch). We show below that (86) captures various word order 
restrictions on RNR, but we first explain how the above bears on the issue of parsimony.

Although we proposed (86) as a solution to the difficulties that RNR-MD causes for linearization, it is - at least in in principle - independent of it. After all, multidominance is a syntactic phenomenon, but pruning takes place in the mapping from syntax to phonology. It is therefore expected that (86) may apply to structures other than the one that necessitates it. Crucially, allowing pruning independently of multidominance permits a straightforward account of RNR-E! If (86) applies to the structure in (88), it can prune branch 4, yielding as its output (85), plus a freefloating DP (the instance of [Dp opera] originally attached via branch 4). Assuming that such structural orphans are left unrealized, pruning results in backward ellipsis.

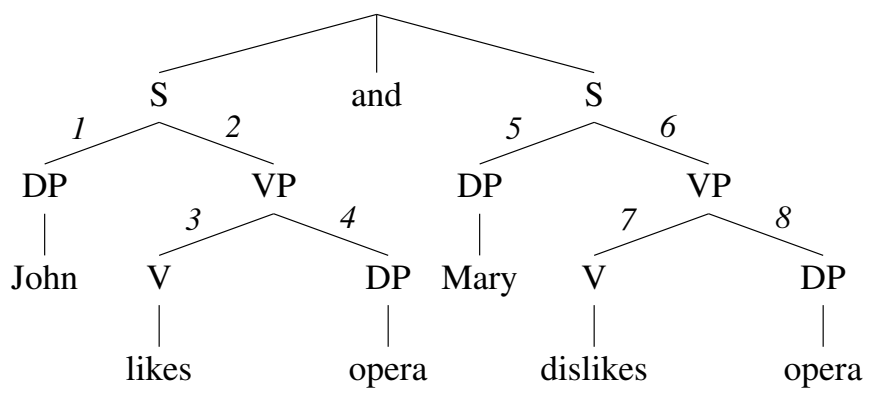

In other words, one version of RNR is the result of multidominance in conjunction with pruning, while the other is the result of pruning only. It is a straightforward consequence of this setup that RNR-MD and RNR-E will share any properties that flow from (86). This, we demonstrate below, solves the problem of parsimony inherent in a dual analysis of RNR.

Our proposal fits well with the view that ellipsis in general results from the non-realization of syntactic structure. It does not fit so well with accounts of regular forward ellipsis that make use of an $e$-feature to regulate the phenomenon (see Merchant 2001 and Van Craenenbroeck and Liptak 2006, a.o.). The presence of such a feature on a head indicates that the phonological value of the head's complement is null. Thus, the presence of $[e]$ on $C$ leads to Sluicing and its presence on T leads to VP ellipsis. This is not necessarily at odds with the notion of pruning - one could assume that the presence of $[e]$ on a head instructs PF to prune the branch pointing to the head's complement. The issue is rather that in the case of RNR-E it is not 
possible to identify a head that would carry the $e$-feature. Thus, RNR-E must on the one hand be treated as an instance of non-realization (given its similarities with regular forward ellipsis), and on the other hand have a license distinct from $[e]$. Our claim is that the rule in (86) provides this license.

Let us now consider what empirical implications (86) has. In both (84) and (88), the two conjuncts count as parallel clauses if John and Mary and likes and dislikes are contrasted. On such a construal, each conjunct has a focus value consisting of alternative propositions that fit the scheme $[\mathrm{P}(\mathrm{x}$, opera $)]$. Given that each conjunct also instantiates this scheme, the two conjuncts satisfy the definition in (87). Hence, the restriction (86ii) is met: 4 and 8 count as corresponding branches.

This is not enough to prune branch 4. For that to be possible, restriction (86iii) must be met as well. Thus, the ordering statements associated with branch 4 in the left conjunct must be satisfied by the substring that branch 8 yields. As English is an SVO language, the relevant ordering statements for both (84) and (88) are John > likes > opera (where the > symbol signifies precedence). Given that branch 8 , the proxy for branch 4 , is part of the right conjunct, its yield follows both John and likes. Therefore, it is possible to prune branch 4 .

While (86) allows omission of opera in the left conjunct in both (84) and (88), it rules out examples such as *John likes opera and Mary dislikes, where the gap is located in the right conjunct and the pivot in the left conjunct. This output would require pruning of branch 8 in (84) and (88), resulting in the representation in (89).

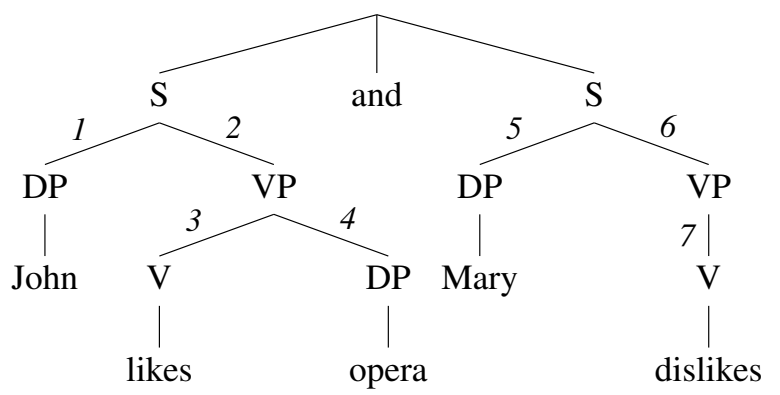

A derivation that transforms (84) or (88) into (89) would not violate the parallelism requirement 
in (86ii) (given an appropriate information-structural construal of the example). It would, however, violate the restriction in (86iii). This is because opera in the left conjunct cannot satisfy the ordering statements generated in the dependent domain, which in this case is the right conjunct. In particular, branch 8 in the dependent domain points to a position following Mary and dislikes, giving rise to the order Mary > dislikes > opera. However, the pivot is located in the left conjunct and therefore precedes both Mary and dislikes. The implication is that pruning branch 8 is not permitted, so that neither ellipsis nor multidominance can give rise to (89).

The rule in (86) also captures the fact that there may not be material in the left conjunct that follows the apparent gap (see Wilder 1999 and Whitman 2009):

(90) *John bought, for Mary and Bill wrapped, a book about opera.

The example in (90) has the structure in (91a) on the ellipsis analysis and the one in (91b) on the multidominance analysis. The rule in (86) does not permit pruning in either structure. The reason for this does not lie in restriction (86ii) - the two conjuncts are parallel structures under an appropriate assignment of focus as long as the predicate in the first conjunct is construed as $\lambda y \lambda x \cdot b u y-f o r-M a r y(x, y)$. The problem is rather that restriction (86iii) cannot be met. The ordering statements associated with the left conjunct are Jobn $>$ bought $>$ a book about opera $>$ for Mary. Pruning of branch 6 requires that its proxy, branch 10, satisfies these. However, it cannot: branch 10 is part of the second conjunct and so its yield follows rather than precedes for Mary. Hence, ellipsis is not possible in (91a), and (91b) violates the no-tangling condition. ${ }^{14}$

(91) a.

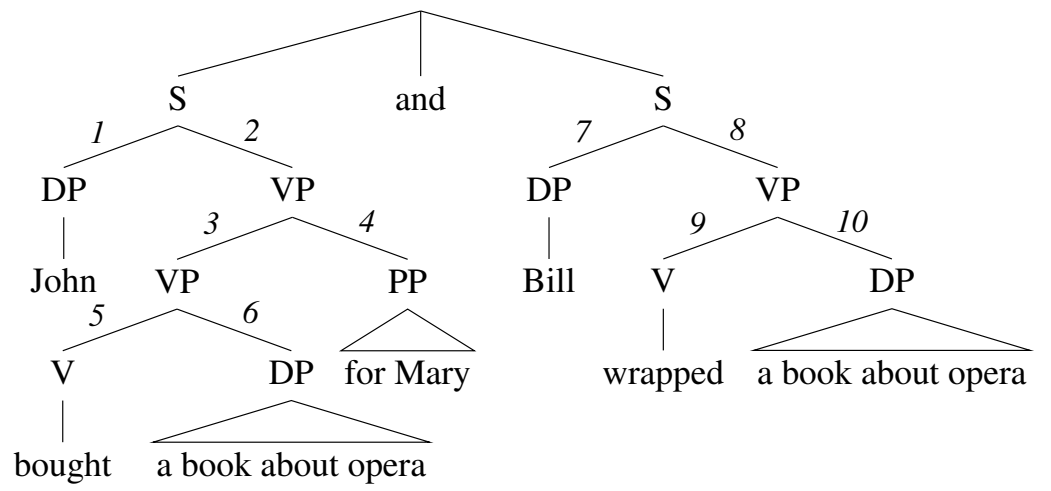


b.

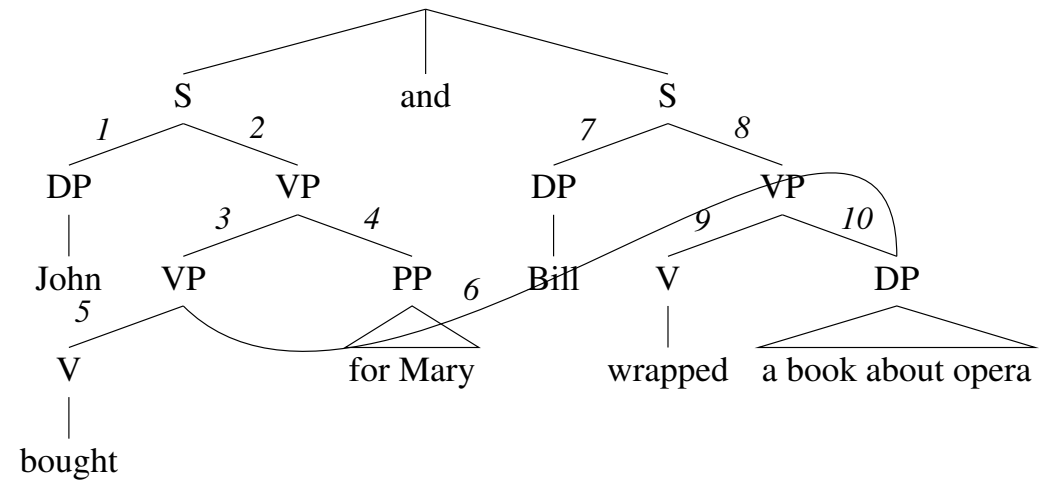

The rule in (86) allows RNR of multiple constituents, as in Mary flattered, and Bill disparaged, John excessively. This example can be represented as in (92a) or (92b).

a.

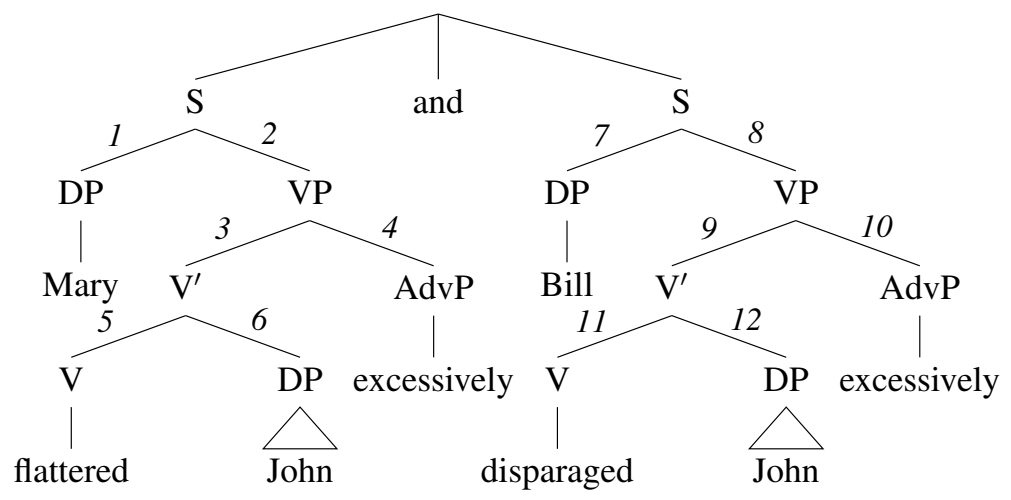

b.

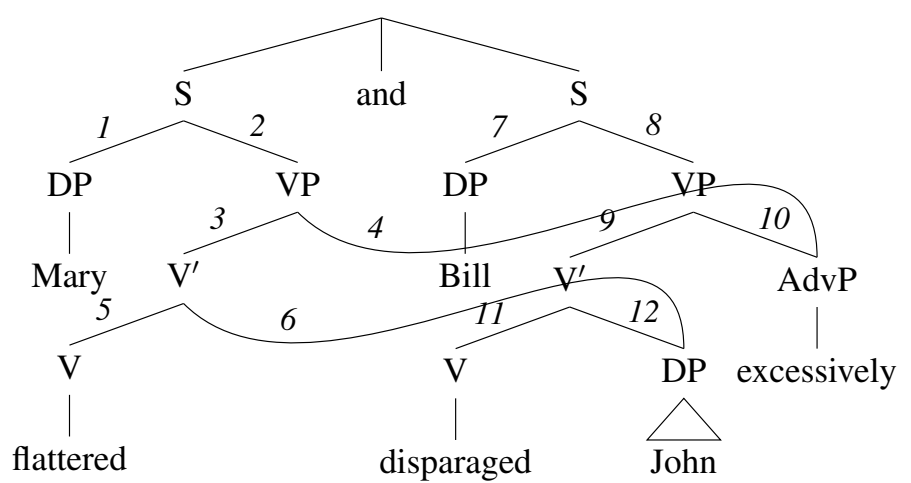

Restriction (86ii) is satisfied if Mary and Bill, and flattered and disparaged are contrasted. Restriction (86iii) is satisfied as well. The ordering statements associated with the left conjuncts in (92a,b) are Mary $>$ flattered $>$ John $>$ excessively. As branches 6 and 4 are paired with branches 12 and 10 , the yield of the latter must follow Mary and flattered, which is the case. In addition, the yield of 10 (branch 4's proxy) must follow the yield of 12 (branch 6 's proxy). Again, this is the case: exces- 
sively follows John. As a consequence, (92a) and (92b) can be pruned to yield (93) (by first removing branch 4 and then branch 6). This gives rise to ellipsis in the case of (92a) and circumvents a violation of the no-tangling condition in the case of (92b).

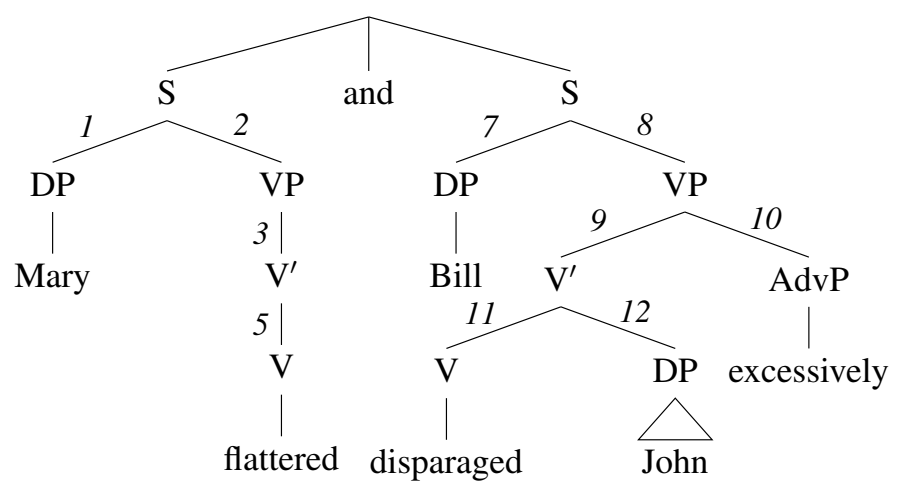

So far, parallelism has only been used to determine which branches are paired in the input structures for pruning. However, given the way the proposal is set up, one would expect certain instances of RNR to be ruled out because the antecedent and dependent domains are not parallel. Such cases exist (see also Yatabe 2003). Consider an example like* John likes, but opera is the bane of Mary's life, which is structured as in (94a) or (94b).

(94) a.

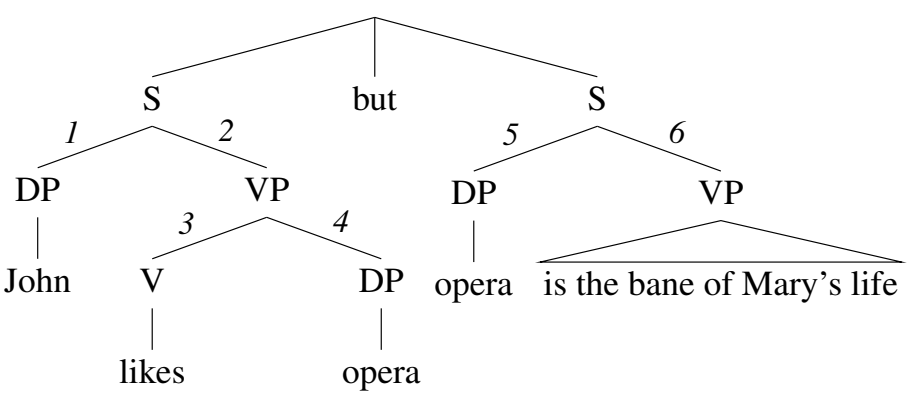

b.

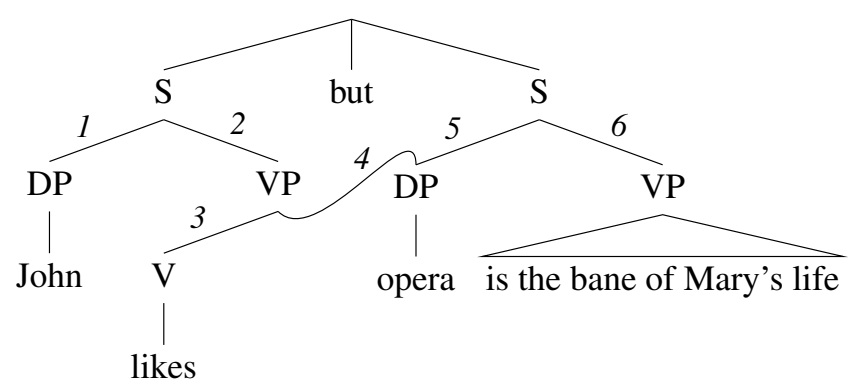

In neither of these representations is pruning possible. This is not because of restriction (86iii). 
Pruning of branch 4 would be possible if it could be paired with branch 5 . The ordering statements associated with left conjuncts in $(94 \mathrm{a}, \mathrm{b})$ are John $>$ likes $>$ opera. As branch 5 is part of the right conjunct, its yield does indeed follow John and likes. The problem is rather that branch 5 cannot be a proxy for branch 4 , because the conjuncts in $(94 \mathrm{a}, \mathrm{b})$ do not meet the definition of parallel structures in (87). Suppose that John and Mary are contrasted, as are like and be-the-bane-of. Then the left conjunct generates a set of alternatives of the shape $\mathrm{P}(\mathrm{x}$, opera $)$, while the right conjunct generates alternatives of the shape $\mathrm{P}($ opera, $y)$. But this implies that the ordinary value of neither conjunct is contained in the focus value of the other. This lack of parallelism blocks pruning. Hence, (94a) does not permit ellipsis, and (94b) violates the no-tangling condition.

We next consider RNR in non-coordinate contexts:

(95) A man who likes, married a woman who dislikes opera.

Like other instances of RNR, examples such as (95) require pruning: this is what gives rise to ellipsis. Hence, both (86ii) and (86iii) must be met, which will only be the case if the subject and object in (95) can be construed as parallel structures. As parallelism is defined in terms of focus semantics and focus semantics has to do with propositions rather than arguments, the definition in (87) is not sufficient. We propose the additional definition of parallel arguments in (96).

(96) $\mathrm{A}$ and $\mathrm{B}$ are parallel arguments iff $[\Phi \llbracket \mathrm{A} \rrbracket]_{\mathrm{o}} \in[\Phi \llbracket \mathrm{B} \rrbracket]_{\mathrm{f}} \wedge[\Phi \llbracket \mathrm{B} \rrbracket]_{\mathrm{o}} \in[\Phi \llbracket \mathrm{A} \rrbracket]_{\mathrm{f}}$.

This definition states that to check whether two DPs are parallel arguments, one must consider what happens when they appear in otherwise identical clauses. If the ordinary value associated with the first clause is part of the focus value associated with the second clause, and vice versa, the DPs count as parallel. Consequently, parallel DPs must be (roughly) isomorphic in terms of syntax and information structure, much like parallel clauses. In (95), a man who likes opera and $a$ woman who dislikes opera count as parallel if man and woman and likes and dislikes are contrasted.

If the subject and object in (95) are indeed parallel structures, the restriction in (86iii) poses no particular problems. The ordering statements that hold of the dependent domain (that 
is, the subject) are $a$ man $>$ who $>$ likes $>$ opera. Given that the object follows the subject, the branch pointing to opera in the object can function as a proxy for the branch pointing to opera in the subject. Therefore, the conditions for pruning (and hence ellipsis) are met.

It follows that RNR in non-coordinate structures is conditioned in much the same way as RNR in coordinate structures: the dependent domain cannot follow the antecedent domain (see (97a)), and the gap must be located at the right edge of the dependent domain (see (97b)). ${ }^{15}$

(97) a. *A man who likes opera, married a woman who dislikes.

b. *A man who likes a lot, married a woman who dislikes opera.

We finally turn to structures in which a primary pivot created through ellipsis contains a secondary pivot created through multidominance. Such structures were instrumental in explaining the interaction between RNR-E and RNR-MD, as they captured the contrast between the PIE-PIM and PIM-PIE orders. Pivot-internal RNR gives rise to two questions that can be answered by assuming a specific order of operations. In particular, the data fall into place if forced pruning (pruning required to satisfy the no-tangling condition) precedes free pruning (pruning that leads to ellipsis).

Firstly, as raised in section 5, a possible objection against the structure proposed for (98a) is that the secondary pivot the same language is simultaneously pronounced and contained in an elided category. It is not self-evident that this should be allowed, especially not in view of (98b), which shows (much like (7b)) that a RNR pivot cannot survive forward ellipsis of VP.

(98) a. Ava will soon be, and Habib is going to, study the same INT language.

b. *Ava will soon be studying, and Habib is going to $e_{\mathrm{VP}}$, the same $\mathrm{INT}_{\mathrm{INT}}$ language.

What distinguishes (98a) and (98b)? Both have the syntactic structure in (99). The order in (98a) is derived by two applications of (86): first branch 3 is pruned (as an instance of forced pruning) and then branch 1 is pruned (as an instance of free pruning). Pruning of branch 3 in effect removes the DP from $\mathrm{VP}_{\mathrm{a}}$. Subsequent pruning of branch 1 leads to ellipsis of $\mathrm{VP}_{\mathrm{a}}$. This does not 
imply that the DP cannot be pronounced, however, as it is no longer contained in $\mathrm{VP}_{\mathrm{a}}$.

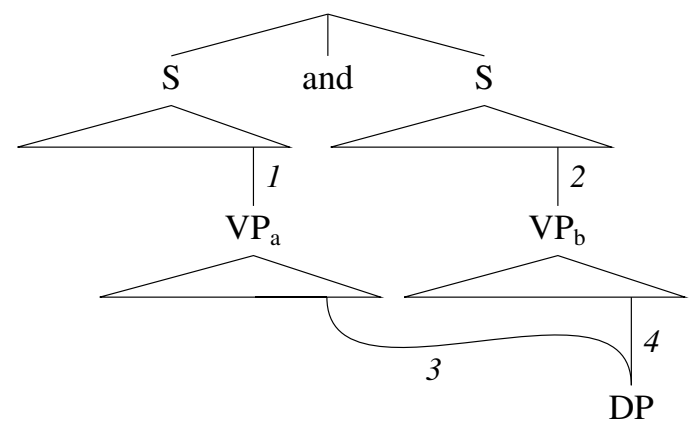

The order in (98b) is derived by forced pruning of branch 3, followed by ellipsis of $\mathrm{VP}_{\mathrm{b}}$ (which we may model as free pruning of branch 2). The second operation removes $\mathrm{VP}_{\mathrm{b}}$, including the $\mathrm{DP}$, from the structure. However, if $\mathrm{VP}_{\mathrm{b}}$ is removed, then none of its parts can be realized, which explains why (98b) is ungrammatical. (Note that the DP cannot be left unrealized altogether, as that would render it unrecoverable.) Thus, the contrast between (98a) and (98b) is explained.

The second question we must address has to do with the assumption that a secondary pivot must be rightmost within the first conjunct, even though the constituent that contains it is elided (see (48)). On this assumption, ellipsis of $\mathrm{VP}_{\mathrm{a}}$ in (100) does not ameliorate the ungrammaticality of the DP undergoing non-order-preserving RNR and so PIM-PIE orders are ruled out.

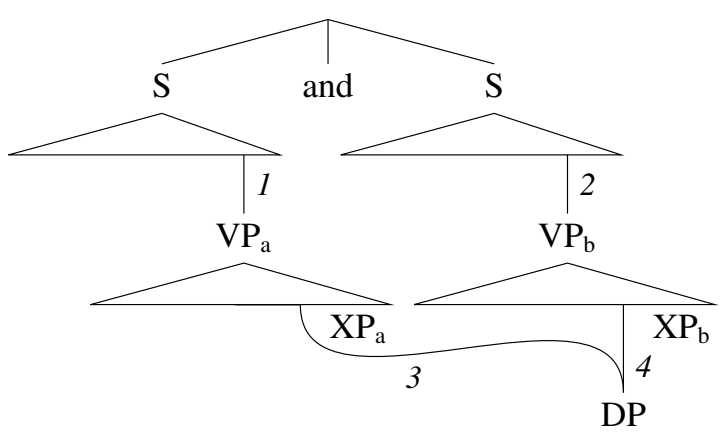

Why should this be? After all, silent material is irrelevant to linear constraints. The answer to this question again lies in the order of operations at PF. Forced pruning of branch 3 in (100) must take place before free pruning of branch 1 (ellipsis of $\mathrm{VP}_{\mathrm{a}}$ ). However, pruning of branch 3 is not permitted in the presence of $\mathrm{XP}_{a}$, and - crucially - removal of $\mathrm{XP}_{\mathrm{a}}$ relies on pruning of branch 1 . 
Hence, there is no coherent derivation that can delete branches 1 and 3 - as required.

In conclusion, we have shown that a simple rule of pruning suffices to explain why RNR-E and RNR-MD behave alike. Pruning is necessary to reconcile RNR-MD with the notangling condition. When applied elsewhere, it gives rise to RNR-E. In other words, the issue of parsimony, which any dual analysis of RNR faces, dissolves: the shared properties follow from a shared rule.

\section{Concluding Remarks: Predicted variation in RNR grammars}

Let us take stock. We have reached the following main conclusions. (i) In coordinate structures, RNR is ambiguous between ellipsis and multidominance; elsewhere, it must be ellipsis. (ii) Cumulative agreement in RNR structures is semantic and is a consequence of the impossibility of regular syntactic agreement under multidominance. (iii) A ban on branching movement chains explains why multidominance is required for ATB movement. This in turn explains why RNRMD is exceptional in allowing the pivot (or material in it) to scope over a coordinate structure. (iv) The parallel behavior of RNR-E and RNR-MD follows from the fact that both rely on pruning at the PF interface: RNR is either multidominance and pruning or pruning only.

We close the paper with a brief exploration of the parameter space that our proposal may give rise to. Simplifying matters considerably, we may suppose that there are four relevant parameters. Those in (101a) and (101b) determine whether RNR-MD and/or RNR-E are available (and hence also whether a grammar permits RNR at all). ${ }^{16}$ The parameter in (101c) determines whether in grammars with RNR-E there is a requirement of strict identity between the ellipsis site and the corresponding overt material (bearing on the grammaticality of agreement mismatches, pronominal mismatches and vehicle change). Finally, the parameter in (101d) determines whether in grammars with RNR-MD cumulative agreement is licensed.

(101) a. RNR can be MD \{yes, no\}

b. RNR can be $\mathrm{E}\{$ yes, no $\}$ 
c. Recovery under (backward) ellipsis is tolerant of mismatches \{yes, no\}

d. $[\mathrm{PL}]$ on $\mathrm{V}$ can be interpreted $\{$ yes, no

A positive setting of (101a) implies that (elements within) the pivot can undergo LF raising out of a coordinate structure ('cross-coordinate raising'), which bears on quantifier scope, internal readings of relational adjectives and distributive readings of plurals. A positive setting of (101b) implies that RNR can be found in non-coordinate structures. The table below indicates what data are generated by the permitted grammars:

\begin{tabular}{ccc|cccc}
\hline & Tolerant & {$[\mathrm{PL}]$ on V inter- } & Cumulative & Morph. & Cross-coordi- & Non-coord. \\
& recovery & pretable & agreement & mismatches & nate raising & RNR \\
\hline \multirow{2}{*}{ RNR-MD + } & Yes & Yes & Yes & Yes & Yes & Yes \\
RNR-E & No & Yes & Yes & No & Yes & Yes \\
& Yes & No & No & Yes & Yes & Yes \\
& No & No & No & No & Yes & Yes \\
\hline \multirow{2}{*}{ RNR-MD } & - & Yes & Yes & No & Yes & No \\
& - & No & No & No & Yes & No \\
\hline \multirow{2}{*}{ RNR-E } & Yes & - & No & Yes & No & Yes \\
& No & - & No & No & No & Yes
\end{tabular}

Table III: Possible RNR grammars (left), with their empirical profile (right)

The judgments we have reported are those associated with the top-most grammar in Table III. As they stand, the less permissive grammars in table III are mere theoretical possibilities, although there is reason to believe that they may characterize the I-language of certain speakers. The experimental data reported in Kluck 2009, for example, suggest that some Dutch speakers allow morphological mismatches, while others do not. Similarly, while Grosz (2015) reports that Dutch lacks cumulative agreement, it is acceptable in the judgment of one of the authors and two other native speakers. Finally, an anonymous reviewer reports that in their Dutch, RNR permits neither cumulative agreement, nor morphological mismatches, nor internal readings of relational adjectives (as in the least permissive grammar in table III). However, the Dutch co-author 
and the two other speakers we have consulted are much more permissive and allow all three phenomena.

More interesting than the patterns that are permitted are the ones our proposal rules out. The predicted restrictions can be expressed in three statements of entailment. First, if a grammar permits cumulative agreement, it must have RNR-MD and will therefore also permit cross-coordinate raising (entailment A). Second, if a grammar permits morphological mismatches under RNR, it must have RNR-E and will therefore also permit RNR in non-coordinate environments (entailment B). Third, if a grammar permits RNR at all, it must have either RNR-MD or RNR-E or both, and hence it will also permit either cross-coordinate raising or RNR in non-coordinate environments or both (entailment C). These three entailments jointly rule out half of the a priori possible empirical profiles for RNR in a given speaker. We show this in table IV: ${ }^{17}$

\begin{tabular}{cccccc}
\hline RNR & Cumulative & Morph. & Cross-coordinate & Non-coord. & Out by \\
& agreement & mismatches & raising & RNR & \\
\hline Yes & Yes & Yes & Yes & No & B \\
Yes & Yes & Yes & No & Yes & A \\
Yes & Yes & Yes & No & No & A, B \\
Yes & Yes & No & No & Yes & A \\
Yes & Yes & No & No & No & A \\
Yes & No & Yes & Yes & No & B \\
Yes & No & Yes & No & No & B \\
Yes & No & No & No & No & C
\end{tabular}

Table IV: Empirical profiles ruled out

Thus, there is a parametric interpretation of our proposal that may be flexible enough to capture known variation in the grammar of RNR and still be restrictive enough to be falsifiable. At present, not enough is known about crosslinguistic and inter-speaker variation in RNR to evaluate the extent to which the model we have sketched fits reality. 


\section{References}

Abbott, Barbara. 1976. Right node raising as a test for constituenthood. Linguistic Inquiry 7: 639_ 642.

Abels, Klaus. 2004. Right Node Raising: Ellipsis or across the board movement. In Proceedings of NELS 34, ed. by K. Moulton and M. Wolf, 45-59. Amherst, MA: GLSA.

Abels, Klaus, and Ad Neeleman. 2012. Linear asymmetries and the LCA. Syntax 15: 25-74.

Ackema, Peter, and Ad Neeleman. 2004. Beyond morphology; Interface conditions on word formation. Oxford: Oxford University Press.

Ackema, Peter, and Ad Neeleman. 2018. Features of person; From the inventory of persons to their morphological realization. Cambridge, MA: MIT Press.

Bachrach, Asaf, and Roni Katzir. 2007. Spelling out QR. In Proceedings of Sinn und Bedeutung 11, ed. by E. Puig-Waldmüller, 63-75. Barcelona: Universitat Pompeu Fabra.

Bachrach, Asaf, and Roni Katzir. 2009. Right-node raising and delayed spellout. In Interphases: Phase-theoretic investigations of linguistic interfaces, ed. by K. Grohmann, 283-316. Oxford: OUP.

Barker, Chris. 2007. Parasitic scope. Linguistics and Philosophy 30: 407-444.

Barlow, Michael. 1992. A situated theory of agreement. New York: Garland.

Barros, Matthew, and Luis Vicente. 2011. Right node raising requires both ellipsis and multidomination. In University of Pennsylvania Working Papers in Linguistics, 17:1, Article 2.

Beavers, John, and Ivan Sag. 2004. Coordinate ellipsis and apparent non-constituent coordination. In Proceedings of the 11th International Conference on Head-Driven Phrase Structure Grammar (HPSG 2004), ed. by Stefan Müller, 48-69. Stanford: CSLI Publications.

Bošković, Željko. 2004. Two notes on right node raising. In Cranberry Linguistic 2 (University of Connecticut Working Papers in Linguistics 12), ed. by M. Rodríguez-Mondoñedo and M.E. Ticio, 13-24. Cambridge, MA: MITWPL.

Bošković, Željko, and Steven Franks. 2000. Across-the-board movement and LF. Syntax 3: 107- 
128.

Brody, Michael. 1997. Perfect chains. In Elements of grammar, ed. by L. Haegeman, 139-167. Dordrecht: Kluwer.

Carlson, Greg. 1987. Same and different. Some consequences for syntax and semantics. Linguistics and Philosophy 10: 531-565.

Chaves, Rui Pedro. 2014. On the disunity of right-node raising phenomena: Extraposition, ellipsis, and deletion. Language 90: 834-886.

Citko, Barbara. 2005. On the nature of Merge: External Merge, Internal Merge, and Parallel Merge. Linguistic Inquiry 36: 475-496.

Citko, Barbara. 2011. Symmetry in syntax; Merge, Move and labels. Cambridge: CUP.

Davis, Anthony. 1992. Empty heads and missing subjects: Underspecification in Hausa VPs. In Proceedings of Chicago Linguistic Society 28 (Volume 1), ed. by In C.P. Canakis, G.P. Chan, and J. Marshall Denton, 94-108. Chicago: CLS.

De Vos, Mark, and Luis Vicente. 2005. Coordination under right node raising. In Proceedings of WCCFL 24, ed. by John Alderete, Chung-hye Han, and Alexei Kochetov, 97-104. Somerville: Cascadilla Press.

De Vries, Mark. 2007. Invisible constituents? Parentheticals as B-Merged adverbial phrases. In Parentheticals, ed. by Nicole Dehé and Yordanka Kavalova, 203-234. Amsterdam: John Benjamins.

De Vries, Mark. 2009. On Multidominance and linearization. Biolinguistics 3: 344-403.

Fiengo, Robert, and Robert May. 1994. Indices and identity. Cambridge, MA: MIT Press.

Fox, Danny 2000. Economy and semantic interpretation. Cambridge, MA: MIT Press.

Gärtner, Hans Martin. 2002. Generalized transformations and beyond: Reflections on minimalist syntax. Berlin: Akademie Verlag.

Gazdar, Gerald, Ewan Klein, Geoffrey Pullum and Ivan Sag. 1985. Generalized phrase structure grammar. Cambridge, MA: Harvard University Press. 
Goodall, Grant 1987. Parallel structures in syntax. Cambridge: Cambridge University Press.

Gracanin-Yuksek, Martina. 2013. Linearizing multidominance structures. In Challenges to linearization, ed. by Theresa Biberauer and Ian Roberts, 269-294. Berlin: Mouton de Gruyter.

Grosu, Alexander. 1976. A note on Subject Raising to Object and Right Node Raising. Linguistic Inquiry 7: 642-645.

Grosz, Patrick. 2015. Movement and agreement in right-node-raising constructions. Syntax 18: $1-38$

Grodzinsky, Yosef, and Tanya Reinhart. 1993. The innateness of binding and coreference. Linguistic Inquiry 24: 69-101.

Guimarães, Maximiliano. 2004. Derivation and representation of syntactic amalgams. PhD dissertation, University of Maryland.

Ha, Seungwan. 2008. Ellipsis, right node raising, and across-the-board constructions. Doctoral Dissertation, Boston University.

Hartmann, Katharina. 2000. Right node raising and gapping: Interface conditions on prosodic deletion. John Benjamins: Amsterdam.

Heim, Irene. 1991. Artikel und Definitheit [Articles and definiteness]. In Semantik: Ein internationales Handbuch derzeitgenössischen Forschung, ed. by Arnim von Stechow and Dieter Wunderlich, 487-535. Berlin: de Gruyter.

Hiraiwa, Ken, and Adams Bodomo. 2008. Object-sharing and symmetric sharing: Predicate-clefting and serial verbs in Daagare. Natural Language and Linguistic Theory 26: 795-832.

Hirsch, Aron, and Michael Wagner. 2015. Right node raising, scope, and plurality. In Proceedings of the 20th Amsterdam Colloquium, ed. by Thomas Brochhagen, Floris Roelofsen, and Nadine Theiler, 187-196. Amsterdam: ILLC.

Hudson, Richard. 1976. Conjunction reduction, gapping, and right node raising. Language $52: 535-562$.

Jackendoff, Ray. 1977. X' syntax: A study of phrase structure. Cambridge, MA.: MIT Press. 
Kasai, Hironobu. 2007. Multidominance in syntax. PhD dissertation, Harvard University.

Kayne, Richard. 1994. The antisymmetry of syntax. Cambridge, MA: MIT Press.

Kluck, Marlies. 2008. Sentence amalgamation. PhD dissertation, University of Groningen.

Kluck, Marlies. 2009. Good neighbors or far friends. Matching and proximity effects in Dutch right node raising. Groninger Arbeiten zur Germanistischen Linguistik 48: 115-158.

Lakoff, George. 1974. Syntactic amalgams. In Papers from the 10th regional meeting of the Chicago Linguistic Society, ed. by Michael La Galy, Robert Fox, and Anthony Bruck, 321-344. Chicago: University of Chicago.

Larson, Bradley. 2012. A dilemma with accounts of right node raising. Linguistic Inquiry 43: 143150.

Link, Godehard. 1983. The logical analysis of plurals and mass terms: A Lattice Theoretical approach. In Meaning, use and interpretation of language, ed. by Rainer Bäuerle, Christoph Schwarze, and Arnim von Stechow, 245-257. Berlin: De Gruyter.

McCawley, James 1982. Parentheticals and discontinuous constituent structure. Linguistic Inquiry 13: 91-106.

McCloskey, James. 1986. Right node raising and preposition stranding. Linguistic Inquiry 17:183186.

Merchant, Jason. 2013. Diagnosing ellipsis. In Diagnosing syntax, ed. by Lisa Cheng and Norbert Corver, 537-542. Oxford: Oxford University Press.

Moltmann, Friederike 1992. Coordination and comparatives, PhD dissertation, MIT.

Muadz, Husni. 1991. Coordinate structures: A planar representation. PhD dissertation, University of Arizona.

Neeleman, Ad, Joy Philip, Misako Tanaka, and Hans van de Koot. 2021. Subordination and binary branching. To appear in Syntax.

Neeleman, Ad, and Hans van de Koot. 2010. A local encoding of syntactic dependencies and its consequences for the theory of movement. Syntax 13: 331-372. 
Partee, Barbara, Ava ter Meulen, and Robert E. Wall. 1993. Mathematical methods in linguistics. Dordrecht: Kluwer.

Philip, Joy. 2012. Subordinating and coordinating linkers. PhD dissertation, UCL.

Pollard, Carl, and Ivan Sag. 1994. Head-driven phrase structure grammar. Chicago: University of Chicago Press.

Postal, Paul. 1974. On raising. Cambridge, MA: MIT Press.

Postal, Paul. 1998. Three investigations of extraction. Cambridge, MA: MIT Press.

Reinhart, Tanya. 1983. Anaphora and semantic interpretation. London: Croom Helm.

Reinhart, Tanya. 1987. Specifiers and operator binding. In The representation of (in)definiteness, ed. by Eric Reuland and Alice ter Meulen, 130-167. Cambridge, MA: MIT Press.

Reuland. Eric. 2001. Primitives of binding. Linguistic Inquiry 32: 439-492.

Reuland, Eric. 2011. Anaphora and language design. Cambridge, MA: MIT Press.

Rodman, Robert. 1976. Scope phenomena, "movement transformations," and relative clauses. In Montague grammar, ed. by Barbara Partee, 165-176. New York: Academic Press.

Ross, John Robert. 1967. Constraints on variables in syntax. PhD dissertation, MIT.

Rooth, Mats. 1992. A theory of focus interpretation. Natural Language Semantics 1:75-116.

Ruys, Eddy. 1992. The scope of indefinites. PhD dissertation, Utrecht University.

Sabbagh, Joseph. 2007. Ordering and linearizing rightward movement. Natural Language and Linguistic Theory 25: 349-401.

Sauerland, Uli. 2008. Implicated presuppositions. In The discourse potential of underspecified structures, ed. by Anita Steube, 581-600. Berlin: De Gruyter Mouton.

Shieber, Stuart. 1986. An introduction to unification-based approaches to grammar. Stanford: CSLI.

Shiraïshi, Aoi, Anne Abeillé, Barbara Hemforth and Philip Miller. 2019. Verbal mismatch in right-node raising. Glossa 4: 114. 1-26.

Starke, Michal. 2001. Move dissolves into Merge: A theory of locality. PhD Dissertation, University of Geneva. 
Valmala, Vidal. 2013. On right node raising in Catalan and Spanish. Catalan Journal of Linguistics 12: 219-251.

Van Riemsdijk, Henk. 1998. Trees and scions - science and trees. Festwebpage for Noam Chomsky. Cambridge, MA: MIT Press.

Van Riemsdijk, Henk. 2000. Free relatives inside out; Transparent free relatives as Grafts. In Proceedings of the 8th Annual Conference of the Polish Association for the Study of English., ed. by Bozena Rozwadowska, 223-233. Wroclaw: Aksel.

Van Riemsdijk, Henk. 2006. Grafts follow from Merge. In Phases of interpretation, ed. by Mara Frascarelli, 17-44. Berlin: Mouton de Gruyter. (pp.)

Vicente, Luis. 2009. A note on the copy vs. multidominance theories of movement. Catalan Journal of Linguistics 8:1-23.

Yatabe 2003. A linearization-based theory of summative agreement in peripheral-node raising Constructions. In Proceedings of the 9th International Conference on HPSG, ed. by J.-B. Kim \& S. Wechsler, 391-411. Stanford: CSLI.

Wexler, Kenneth, and Peter Culicover. 1980. Formal principles of language acquisition. Cambridge, MA: MIT Press.

Wilder, Chris. 1997. Some properties of ellipsis in coordination. In Studies on Universal Grammar and typological variation, ed. by Artemis Alexiadou and T. Alan Hall, 59-107. Amsterdam: John Benjamins.

Wilder, Chris. 1999. Right node raising and the LCA. In Proceedings of WCCFL 18, ed. by Sonya Bird et al., 586-598. Somerville: Cascadilla Press.

Winter, Yoad. 2002. Atoms and sets: A characterization of semantic number. Linguistic Inquiry 33: 493-505.

Whitman, Neal. 2009. Right-node wrapping: Multimodal categorial grammar and the "friends in low places" coordination. In Theory and evidence in semantics, ed. by Erhard Hinrichs and John Nerbonne, 235-256. Standford: CSLI. 
Williams, Edwin. 1978. Across-the-board rule application. Linguistic Inquiry 9: 31-43.

UCL Linguistics, Chandler House, 2 Wakefield Street, London, WC1N 1PF, UK

zoe.belk@ucl.ac.uk, a.neeleman@ucl.ac.uk, j.philip@ucl.ac.uk

\section{Footnotes}

Earlier versions of this paper were presented at McGill University, Leiden University, and the University of Nova Gorica. We would like to thank the audiences for useful questions and comments. Constructive criticism from two anonymous reviewers, guidance from editor Eric Reuland, and detailed feedback from Zheng Shen have led to significant improvements in content and presentation. We are also grateful to the many native speakers and linguists with whom we have discussed right-node raising. These include Klaus Abels, Caitlin Canonica, Anna Grabovac, John Harris, Lily Kahn, Lanko Marušič, Michael Mourounas, Matthew Reeve, Andrea Santi, Hans van de Koot, James White, and Gregor Williamson.

${ }^{1}$ All the data reported reflect the judgments of three native speakers. We have worked with various additional speakers in constructing new data.

${ }^{2}$ That RNR is order-preserving can also be seen from right-node wrapping (Wilder 1999, Whitman 2009), where a constituent belonging to the final conjunct follows the pivot (here: to Mary):

(i) John bought and Ryo gave a book about opera to Mary.

${ }^{3}$ Sabbagh (2007) proposes a movement analysis that addresses some of the above problems, but not the lack of rebracketing in (7) or the option of right-node wrapping illustrated in footnote 2. ${ }^{4}$ Chaves (2014) claims that morphological mismatches are limited to cases that can be analyzed as VP/N' ellipsis, but this is not borne out by the data in Shiraïshi et al. 2019.

${ }^{5}$ This section gives only a partial account of agreement in RNR structures. In particular, quantified phrases behave differently from referential DPs. While indefinites behave as expected, universal and negative quantifiers resist cumulative agreement: 
(i) a. Susan reports that every doctor, and Carla reports that every nurse, has/??have traveled to Cameroon.

b. Susan reports that no doctor, and Carla reports that no nurse, has/*have traveled to Cameroon.

The data in (i) can be captured by appealing to the semantic contribution of number in quantified expressions. Consider a DP like the boys. Its interpretation requires, first of all, the construction of a semilattice through the mapping of a set of atoms to the set of its nonempty subsets. We assume that this is achieved through the attachment of a distributivity operator D (Link 1983). Subsequently, the plural feature selects those subsets with a cardinality larger than one. This procedure characterizes plural definite and indefinite DPs alike, but does not extend to plural universal and negative quantifiers. While these do have a restrictor interpreted as a set of sets (Winter 2002), there is no selection of nonsingleton sets prior to merger of the quantifier (no boys does not mean "no sets of boys with a cardinality larger than one"). In other words, D is attached, but [PL] is not interpreted. We hypothesize that it is present for purely morphosyntactic reasons: D can only appear in the context of [PL]. If so, number in universal and negative quantifiers is not interpreted. This in turn implies that multiple agreement with such quantifiers will not lead to interpretive difficulties, blocking application of the rule in (20) and hence ruling out cumulative agreement.

${ }^{6}$ We rely on (26) to rule out finite predicates that act as pivots in RNR-E. However, we think that the constraint extends to finite clauses (see footnotes 11 and 12). Note that finite predicates can be elided under Stripping in examples such as (ia), but this option disappears when the finite predicate is embedded, as in (ib), and therefore irrelevant to the cases covered by (26).

(i) a. John has stolen a backdoor key and Ryo $e_{T}$, too.

b. *John has stolen a backdoor key and I know that Ryo $e_{T}$, too.

${ }^{7}$ If ATB movement is facilitated by multidominance, one may wonder why it does not give rise 
to cumulative agreement after all. Note, however, that in (i) it is not only the case that the auxiliary's trace cannot enter into regular syntactic agreement (as explained in the previous section), but also that the rule in (20) cannot apply: the plural feature on the auxiliary does not find a predicate that can be marked as holding of a plural individual.

(i) [Susan seen such chaos] When has ${ }^{t_{\text {aux }}}$ and [Helga heard such cacophony]?

What is possible, at least in principle, is for the auxiliary to probe for phi features from its surface position. This would capture the data in (ii) as instances of closest conjunct agreement:

(ii) a. When has/*have [Susan $t_{\text {aux }}$ seen such chaos] and [the neighbors $t_{\text {aux }}$ heard such cacophony]?

b. When have/*has [the neighbors $t_{\text {aux }}$ seen such chaos] and [Helga $t_{\text {aux }}$ heard such cacophony]?

${ }^{8}$ Sabbagh (2007) and Bachrach and Katzir (2007) argue that RNR can facilitate exceptional widescope beyond the data discussed here. However, careful empirical work by Hirsch and Wagner (2015) suggests that this assessment may not be correct (see also Abels 2004 and Chaves 2014). ${ }^{9}$ Barros and Vicente (2011:7) mark (ia) as ungrammatical. While it does seem degraded to us, its status is comparable with (ib), which does not involve a morphological mismatch.

(i) a. ??Alice has, and Beatrix wants to, work on different $t_{\mathrm{INT}}$ topics.

b. ??Alice did, and Beatrix wants to, work on different $\mathrm{INT}_{\mathrm{T}}$ topics.

${ }^{10}$ Larson (2012:148) gives the example in (ia) as fully grammatical. While we find it degraded, it is better than expected. Note, however, that the example is more complex than it needs to be.

When we simplify it, as in (ib), the result is clearly ungrammatical.

(i) Alice needs to decide what topic she's going to present.

a. She $e_{1}$ thinks that she absolutely must, and Bill fears that he won't, present different $\mathrm{INT}_{\mathrm{NT}}$ topics to Alice,'s supervisor. 
b. *She ${ }_{1}$ absolutely must, and Bill won't, present different ${ }_{\mathrm{INT}}$ topics to Alice's ${ }_{1}$ 's supervisor. ${ }^{11}$ The restriction illustrated in (64) should extend to finite pivots. The example in (ia) is indeed reported to be ungrammatical by Larson (2012:148). However, Barros and Vicente (2011:7) judge (ib) to be grammatical. We have no explanation for this surprising discrepancy, which is not in line with our own intuitions (according to which all the examples in (i) are unacceptable). (i) Alice has been campaigning hard for weeks on end, but success hangs in the balance.

a. *She ${ }_{1}$ fears, but Alex said Bob is not worried, that Alice ${ }_{1}$ might lose the election.

b. $\left(^{*}\right)$ She $_{1}$ fears, but Bob is not worried, that Alice $_{1}$ might lose the election.

${ }^{12}$ The restriction illustrated in (66) extends to pivots that are finite clauses. The example in (i) can be used if Claire is convinced that John will finish his paper in time, but not if Claire is convinced that she will finish her paper in time. Thus, (i) does not tolerate a morphological mismatch.

(i) Claire is convinced, but John doubts, that he will finish his paper in time.

${ }^{13}$ Our proposal preserves the insight in Citko 2005 that multidominance is unproblematic if the shared material has no phonological reflex, for instance in the case of overt ATB movement. Hence, such movement is less restricted than covert ATB movement, which must be fed by RNR. The irrelevance of empty categories to linearization also explains how there can be languages like Hausa, which have ATB movement, but lack RNR (Davis 1992 and Beavers and Sag 2004). Overt ATB movement involves multidominance but does not give rise to problems in linearization; RNR, by contrast, will only be found in languages that have the rule in (86) (see also section 8$)$.

${ }^{14}$ Note that (86) does allow material to follow the pivot within the antecedent domain, as this does not violate the ordering restriction imposed on the pivot in the dependent domain. Hence, the proposal permits right-node wrapping (see footnote 2).

${ }^{15}$ Note that RNR in non-coordinate structures also permits right-node wrapping, as in (i). 
(i) A man who likes, married a woman who dislikes opera immensely.

${ }^{16}$ If the proposal in the previous section is on the right track, the parameters in $(101 \mathrm{a}, \mathrm{b})$ must be formulated so as to restrict application of the pruning rule in (86). The parameter in (101a) would state whether violations of the no-tangling condition may be repaired, while the parameter in (101b) would state whether free application of (86) is permitted.

${ }^{17}$ There is a further potential prediction. If the restriction in (26) that a finite pivot cannot be created by RNR-E is universal, a language would have to have a positive setting of (101a) to allow finite pivots. It would then follow that a grammar that permits cumulative agreement must also permit finite pivots (both phenomena would depend on RNR-MD). For the same reason, a grammar permitting cross-coordinate raising would also permit finite pivots, and vice versa. If (26) is not universal, no such effects are predicted. 